\title{
A Three-stage Methodology for Design Evaluation in Product Development
}

Faiz Mohd Turan, Badrul Omar

Faculty of Manufacturing Engineering, Universiti Malaysia Pahang, 26600 Pekan, Pahang, Malaysia

faizmt@ump.edu.my

Faculty of Mechanical and Manufacturing Engineering, Universiti Tun Hussein Onn Malaysia, Parit Raja, 86400

Batu Pahat, Johor, Malaysia

badrul@uthm.edu.my

\begin{abstract}
In order to remain competitive in today's technologically driven world, the faster and more efficient development of innovative products has become the focus for manufacturing companies. In tandem with this, design evaluation plays a critical role in the early phases of product development, because it has significant impact on the downstream development processes as well as on the success of the product being developed. Owing to the pressure of primary factors, such as customer expectations, technical specifications and cost and time constraints, designers have to adopt various techniques for evaluating design alternatives in order to make the right decisions as early as possible. In this work, a novel threestage methodology for design evaluation has been developed. The preliminary stage screens all the criteria from different viewpoints using House of Quality (HoQ). The second stage uses a Fuzzy-Analytical Hierarchy Process (Fuzzy-AHP) to obtain the alternatives weighting and the final stage verifies the ranking of the alternatives by a Rough-Grey Analysis. This method will enable designers to make better-informed decisions before finalising their choice. A case example from industry are presented to demonstrate the efficacy of the proposed methodology. The result of the example shows that the integration of Fuzzy-AHP with HoQ and Rough-Grey Analysis provides a novel alternative to existing methods of design evaluation.
\end{abstract}

\section{Indexing terms/Keywords}

Design evaluation, product development, decision making

\section{Academic Discipline And Sub-Disciplines}

Engineering

\section{SUBJECT CLASSIFICATION}

Engineering Design

\section{TYPE (METHOD/APPROACH)}

Case study research

\section{Council for Innovative Research}

Peer Review Research Publishing System

\author{
Journal: INTERNATIONAL JOURNAL OF COMPUTERS \& TECHNOLOGY
}

Vol 12, No. 6

editor@cirworld.com 


\section{INTRODUCTION}

The product development process is one of transformation from customer requirements to a physical structure with consideration of the various design constraints [1]. For a long time, new product development has been considered an essential element for organisational competitiveness and success [2]. Product development also plays a critical role in the survival and success of manufacturing enterprises and many researchers have improved their understanding of the need for its strategic management [3-7]. However, truly effective product development remains difficult [8]. A study by Minderhoud \& Fraser [9] indicates that product development practices have evolved over recent years as product cost; quality and time-to-market have each become progressively important. In parallel, the rapid pace of technological development has led to shorter product life cycles for many product categories, most notably in consumer electronics.

Following the identification of a market (user need), a total design system, as espoused by Pugh [10], is a systematic activity that is necessary to produce and sell a successful product to satisfy that need; the activity encompasses product, process, people and organisation. In accordance with this, Ebuomwan et al. [11] proposed that the total design activity model consists principally of a central design core, which in turn comprises a market (user need), product design specification, conceptual design, detailed design, manufacture and sales. Pahl et al. [12] classify the activities of designers into conceptualising, embodying, detailing and computing, drawing and collecting information. Furthermore, Finger \& Dixon [13] mentioned that the mapping between the requirements of a design and the attributes of the artefact is not fully understood. Because the goal of design is to create artefacts that meet functional requirements, further fundamental research is needed on relating the attributes of designs to those functional requirements, that is, on prescribing the artefact. In addition, Chandrasegaran et al., [14] stated that product design is a highly involved, often ill-defined, complex and iterative process and that the needs and specifications of the required artefact become more refined only as the design process moves towards its goal.

In today's industries, product design has become the main focus in a highly competitive environment and fast-growing global market $[15,16]$. The benchmarks used to determine the competitive advantage of a manufacturing company are customer satisfaction, shorter product development time, higher quality and lower product cost [17-19]. Today's product designer is being asked to develop high-quality products at an ever increasing pace [20]. To meet this challenge, new and novel design methodologies that facilitate the acquisition of design knowledge and creative ideas for later reuse are much sought after. In the same context, Liu \& Boyle [21] highlighted that the challenges currently faced by the engineering design industry are the need to attract and retain customers, the need to maintain and increase market share and profitability and the need to meet the requirements of diverse communities. Tools, techniques and methods are being developed that can support engineering design with an emphasis on the customer, the designer and the community [14]. Thus, a good design process should take into account the aforementioned criteria as early as possible in order to ensure the success of a product $[15,16]$.

One important step in designing new products is generating conceptual designs [16]. The conceptual design process includes a set of technical activities, which are the refinement of customer requirements into design functions, new concept development and the embodiment engineering of a new product [1]. A study by Lotter [22] indicates that as much as $75 \%$ of the cost of a product is being committed during the design phase. In the same context, Nevins \& Whitney [23] surmise that up to $70 \%$ of the overall product development cost is committed during the early design phases. Furthermore, Ullman [24] points out that $75 \%$ of the manufacturing cost is committed early in the design process. Under such circumstances, the design concept evaluation in the early phase of product development plays a critical role because it has a significant impact on downstream processes [25]. Similarly, Geng et al. [26] point out that design concept evaluation, which is at the end of the conceptual design process, is one of the most critical decision points during product development. It relates to the ultimate success of product development, because a poor design concept can rarely be compensated in the latter stages.

Design concept evaluation is a complex multi-criteria decision-making (MCDM) process, which involves many factors ranging from initial customer needs to the resources and constraints of the manufacturing company. Concept design selection is the process of evaluation and selection from a range of competing design options with respect to customer needs and other criteria, comparing the relative strengths and weaknesses of the concept design and selecting one or more concept designs for further investigation, testing, or development [27]. However, how to evaluate effectively and objectively design concepts at the early stage of product development has not been well addressed, because the information available is usually incomplete, imprecise, and subjective or even inconsistent [28]. As such, the quest for more effective and objective approaches to evaluate systematically design concepts in the early stage of the design process has invoked much research interest.

The success of the completed design depends on the selection of the appropriate concept design alternative [25, 29, 30]. A mismatch between the customer's need and the product and manufacturing process causes loss of quality, delay to market and increased costs [31]. Changes made early in the design process are less costly than those made during detailed design and later stages [32]. Any design defect in the conceptual design is very difficult to correct in the detailed design stage and will incur further costs in the future [33]. The process of choosing the concept design is frequently iterative and may not produce immediately a dominant concept design [34]. An initially large set of concept design alternatives should be screened down to a smaller set, because some would clearly not be feasible for reasons, such as infeasibility of manufacturing or the cost of production [35]. Failing to choose the most appropriate concept design alternative might lead to reworking or redesigning and waste of resources. To choose a concept design, a company should pay attention to its manufacturing process but also consider the criteria of potential customers. 
In order to help designers become better-informed than conventional method prior to making a judgement, a systematic design evaluation method is needed. Amongst the various tools developed for design concept evaluation, fuzzy set theory and the Analytical Hierarchy Process (Fuzzy-AHP) methods have received the most attention owing to their abilities in handling uncertainty and MCDM [16, 36]. Scott [36] and Ayag \& Odzemir [37] state that AHP is one of the best methods for deciding among a complex criteria structure of different levels, whereas Fuzzy-AHP is a synthetic extension of the classical AHP method in which the fuzziness of the decision makers is considered. The nature of vagueness in design concept evaluation has made this method a topic of considerable interest to many researchers [36, 37]. In accordance with this, an ideal design evaluation method, as espoused by Ayag \& Odzemir [37], Zhai et al. [25] and Turan \& Omar [16], needs to use fewer numbers of design criteria, fewer numbers of pair-wise comparisons and have a support tool to verify and validate the ranking of the alternatives obtained.

The conventional Fuzzy-AHP method aims to use an optimum number of pair-wise comparisons. In AHP, pair-wise comparisons are often preferred by the decision makers, because they facilitate the weighting of criteria and scores of alternatives from comparison matrices, rather than quantifying the weights or scores directly [38]. In many practical situations, the human preference model is uncertain and decision makers might be reluctant or unable to assign exact numerical values to the comparison judgements. Although the use of the discrete scale for performing pair-wise comparative analysis has the advantage of simplicity, a decision maker might find it extremely difficult to express the strength of his preferences and to provide exact pair-wise comparison judgements in relation to the design criteria [39, 40]. Consequently, the decision makers will need a process of reconsideration of design alternatives in relation to the design criteria, which might not help them reduce the number of design criteria. In addition, the final weight of design alternatives might not produce significant differences, which will affect the designers or decision makers when making a judgement. Thus, a sole conventional Fuzzy-AHP is insufficient when applied to ambiguous problems.

With the Fuzzy-AHP method, designers also face the same issues in design evaluation for new product development. A study by Zhai et al. [25] indicates that although the Fuzzy-AHP method offers many advantages for design concept evaluation, it can be a time-consuming process due to the increase in the number of design criteria and design concepts. This might result in a huge evaluation matrix and the need to conduct a large number of pair-wise comparisons, which might lead to low consistency [37].

The proposed design evaluation method will integrate Fuzzy-AHP with another effective method in order to provide the designers with an alternative. A literature search indicates that no work has been done previously on the proposed methodology in design evaluation for new product development. The implementation of the proposed novel method will be divided into three stages: screening, evaluating and verifying, which use fewer numbers of design criteria, fewer numbers of pair-wise comparisons and have a support tool to verify and validate the ranking of the alternatives obtained. Thus, it can fulfil the aforementioned requirement of ideal design evaluation as well as contribute towards the body of knowledge.

This research proposes a novel three-stage method of design evaluation using the integration of Fuzzy-AHP with House of Quality (HoQ) and the Rough-Grey Analysis approach.

\section{RESEARCH FRAMEWORK}

The general framework of the approach is as depicted in Fig 1. The basic idea of this framework is to use problem decomposition to elicit value from different viewpoints, in order to improve the understanding of complex problems [41]. The framework allows decision makers to focus separately on their own decomposed hierarchy with different criteria. The ranking outcome with their associated weights for each decision maker's viewpoint can be obtained by the evaluation methods [42]. In Fig 1, using the prescriptive design process model of Pahl \& Beitz as the base, the proposed design evaluation will focus on the conceptual design and embodiment design stages. The designer or decision maker will initially set up the design structure according to the recommended procedure of the specification to definitive layout process. Then, they can create a general hierarchy and identify the relevant criteria or sub-criteria. The output can be made using a screening process, followed by an evaluation and verification method from each hierarchy with its relevant criteria.

In this research, the HoQ method has been used for screening or pre-evaluating the alternatives suggested by the designer. Prior to this stage, the new contribution, which is the scale of "Weighting criteria" for survey process is introduced. The data from results of survey will be used to compute the priority element for PCM using the new method, which is another contribution in this research. Then, the Fuzzy-AHP method will be used for obtaining the weights of alternatives from the point of view of each decision maker. Finally, before verifying and validating the rank of alternatives using the Rough-Grey Analysis method, another new contribution, which is the method of quantifying the attribute ratings $\otimes v$ is introduced. 
Pahl \& Beitz's model of the design process

Proposed framework

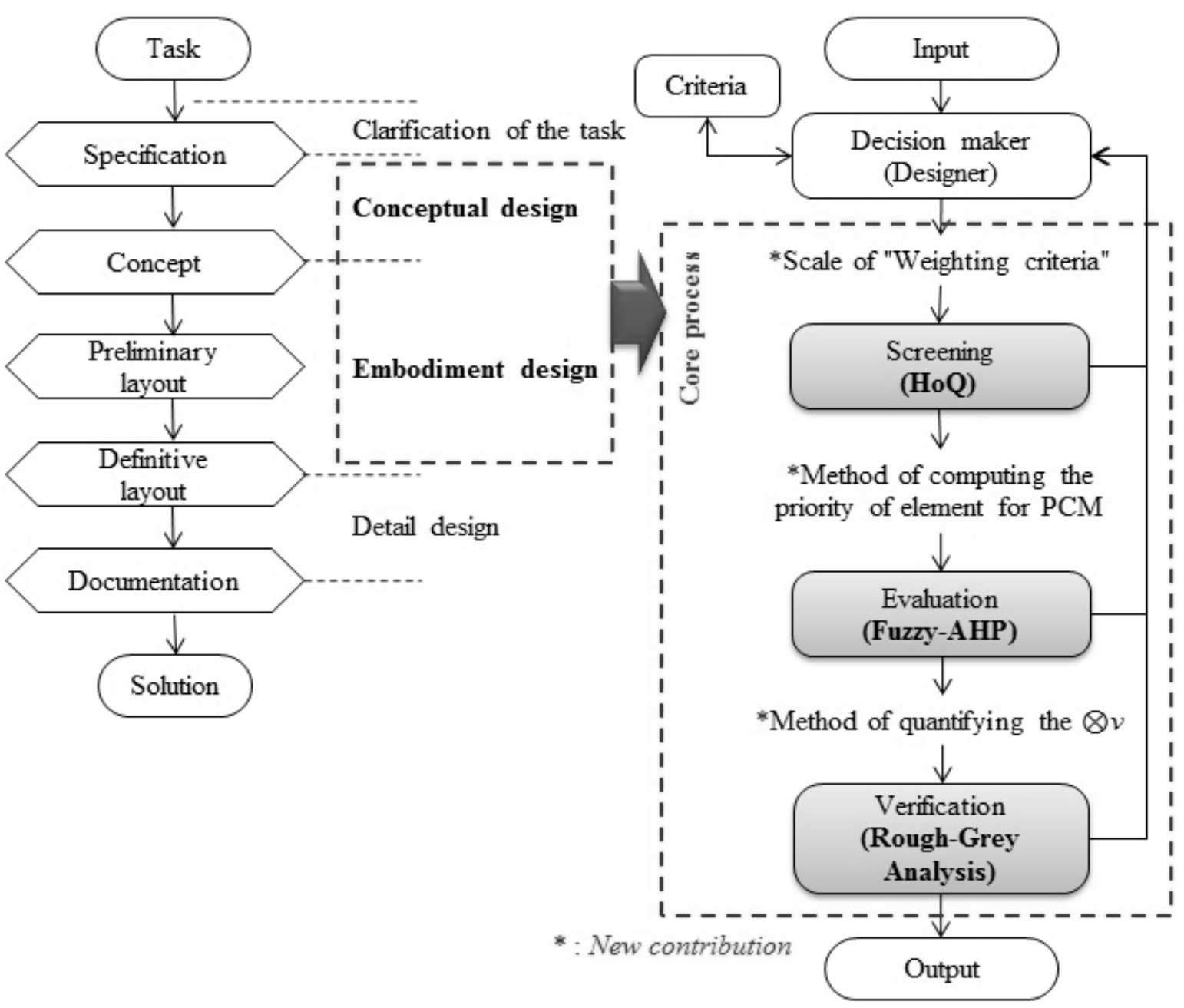

Fig 1: General framework of proposed approach

\section{Scale of "Weighting criteria"}

The scale between 0 - 10 was developed to ease the respondents' group for rating the evaluation criteria, which initially selected by the design engineers based on technical documents and the results of a prior survey. The rating value obtained from the survey then will be used to compute the priority of element for constructing the pair-wise comparison matrix and to quantify the attribute ratings $\otimes v$ at later stage. Table 1 describes the scale of "Weighting criteria" in more detail.

Table 1. Scale of "Weighting criteria"

\begin{tabular}{|c|l|}
\hline $\begin{array}{c}\text { Numerical } \\
\text { rating }\end{array}$ & \multicolumn{1}{|c|}{ Description } \\
\hline 0 & Absolutely useless \\
\hline 1 & Very inadequate \\
\hline 2 & Weak \\
\hline 3 & Tolerable \\
\hline 4 & Adequate \\
\hline 5 & Satisfactory \\
\hline 6 & Good with few drawbacks \\
\hline 7 & Good \\
\hline
\end{tabular}




\begin{tabular}{|c|l|}
\hline 8 & Very good \\
\hline 9 & Exceeding the requirement \\
\hline 10 & Ideal \\
\hline
\end{tabular}

\section{Screening using HoQ}

The present study consisted of two parts. In the first part, the design team drew up the engineering characteristics that would meet a set of predefined customer needs. Next, the design team used the House of Quality to establish the correlations between the customer needs and the engineering characteristics. The second part of the study consisted of an empirical study in which the correlations between the engineering characteristics and the customer needs were derived from the users' evaluations. These two sets of correlations (i.e., the correlation estimates of the design team and the correlations derived from the user evaluations) were then compared with each other in order to assess to what extent the correlations matched (i.e., the extent to which the design team's estimates were accurate). However, first, the customer needs and the engineering characteristics have to be identified.

In short, this part yielded the design team's estimates of the (strengths of the) correlations between the customer needs and engineering characteristics. The second part of the study yielded the users' assessments of the degree to which the set of customer needs was fulfilled. The outcome from this process is the rank of criteria and the higher rank of these criteria will be considered for evaluation in the next process.

\section{Method of computing the priority of element}

The new method of computing the priority of element for constructing the pair-wise comparison matrix before evaluating using Fuzzy-AHP is described in the following paragraphs.

(i) Determine the top seven criteria based on relative weight (relative importance) value from HoQ results, because Saaty proposes a maximum of seven criteria to ensure the consistency of the Fuzzy-AHP operation. Let the relative weight value of $\mathrm{HoQ}$ as $W t_{i}$.

(ii) Identify the rating value of evaluation criteria from respondents' survey results for the top seven criteria as mentioned above. Let the rating value of evaluation criteria as $V_{i}$.

(iii) Determine the weighted value of each evaluation criteria, $W V_{i}$ by multiplying relative weight value of $\mathrm{HoQ}, W t_{i}$ with rating value of evaluation criteria, $V_{i}$, as the equation below:

$$
W V_{i}=W t_{i} \times V_{i}
$$

(iv) Develop the dummy evaluation chart to make a relationship between evaluation criteria and the alternatives for all top seven criteria as shown in Table 2 below:

\section{Table 2. Dummy evaluation chart}

\begin{tabular}{|c|c|c|c|c|c|}
\hline $\boldsymbol{W} \boldsymbol{V}_{\mathbf{1}}$ & $\boldsymbol{W} \boldsymbol{V}_{\mathbf{2}}$ & $\boldsymbol{W} \boldsymbol{V}_{\mathbf{3}}$ & $\ldots$ & $\ldots$ & $\boldsymbol{W} \boldsymbol{V}_{\boldsymbol{n}}$ \\
\hline$W V_{1} / W V_{1}$ & $W V_{1} / W V_{2}$ & $W V_{1} / W V_{3}$ & $\ldots$ & $\ldots$ & $W V_{1} / W V_{n}$ \\
\hline$W V_{2} / W V_{1}$ & $W V_{2} / W V_{2}$ & $W V_{2} / W V_{3}$ & $\ldots$ & $\ldots$ & $W V_{2} / W V_{n}$ \\
\hline$\ldots$ & $\ldots$ & $W V_{3} / W V_{3}$ & $\ldots$ & $\ldots$ & $\ldots V_{3} / W V_{n}$ \\
\hline$\ldots$ & $\ldots$ & $\ldots$ & $\ldots$ & $\ldots$ & $\ldots$ \\
\hline$W V_{n} / W V_{1}$ & $\ldots$ & $\ldots$ & $\ldots$ & $\ldots$ & $W V_{n} W V_{n}$ \\
\hline
\end{tabular}

\section{Evaluation using Fuzzy-AHP}

The proposed Fuzzy-AHP-based methodology provides a framework for prioritisation of alternatives at early stages of the design process. The methodology can be divided into four steps, as described in the following paragraphs.

(i) Benchmarking and building of model hierarchical structure. The proposed Fuzzy-AHP-based methodology provides a framework for prioritisation.

(ii) Construction of pair-wise comparison matrices (PCM). Construct a PCM for all top seven criteria by computing the priorities of elements using the new method as below: 


$$
A=\left[\begin{array}{ccccc}
1 & \frac{W V_{1}}{W V_{2}} & \frac{W V_{1}}{W V_{3}} & \ldots & \frac{W V_{1}}{W V_{n}} \\
\frac{W V_{2}}{W V_{1}} & 1 & \frac{W V_{2}}{W V_{3}} & \ldots & \frac{W V_{2}}{W V_{n}} \\
\ldots \\
\frac{W V_{n}}{W V_{1}} & \cdots & 1 & \ldots & \ldots \\
& & & \ldots & 1
\end{array}\right]
$$

(iii) Calculation of eigenvectors of elements by solving fuzzy PCM. The objective of this step is to compute the relative importance (or principal eigenvector) of all the elements with respect to their adjacent higher-level element in the hierarchy.

(iv) Calculating overall prioritisation weights for each alternative. The overall or total prioritisation weight (TW) of an alternative was calculated by considering the individual weights of all the relevant criteria. Mathematically, it can be represented as follows [43]:

$$
T W_{A k}=\sum_{k} \underset{i \in U i j}{W_{U i j} \times W_{U i j \in A k}} W_{A k} \forall k
$$

where $\underset{i \in U i j}{W_{U i}}$ is the relative importance of the general criterion $U_{i}$ that is relevant to the secondary criteria $U_{i j}, W_{U i j}$ is the relative importance of the secondary criteria $U_{i j}$ that is relevant to the alternatives $A_{k}, W_{A k}$ is the $U i j \in A k$

relative importance of an alternative $A_{k}$ with regard to its next higher-level secondary criterion and $A_{K}$ is the alternatives $k=1,2,3$.

\section{Method of quantifying the attribute ratings}

The new method of quantifying the attribute ratings value, $\otimes v$ as described in the following paragraph:

(i) Develop the dummy attribute ratings chart for all top seven criteria as shown Table 3 below:

\begin{tabular}{|c|c|c|c|c|c|c|c|c|c|}
\hline \multirow[t]{2}{*}{$a_{j}$} & \multirow[t]{2}{*}{$S_{i}$} & \multicolumn{3}{|c|}{ DM 1} & $\ldots$ & $\ldots$ & \multicolumn{3}{|c|}{ DM $K$} \\
\hline & & $V_{i j} T y p$. & $V_{i j} \operatorname{Min}$ & $\boldsymbol{V}_{i j} \operatorname{Max}$ & $\ldots$ & $\ldots$ & $V_{i j}$ Typ. & $V_{i j} \operatorname{Min}$ & $V_{i j} M a x$ \\
\hline \multirow[t]{3}{*}{$a_{1}$} & $S_{1}$ & $V_{11}$ & $V_{11}-0.5$ & $V_{11}+0.5$ & $\ldots$ & & $V_{1 K}$ & $V_{1 K^{-}} 0.5$ & $V_{1 K+} 0.5$ \\
\hline & $S_{2}$ & $V_{21}$ & $V_{21}-0.5$ & $V_{21}+0.5$ & $\ldots$ & & $V_{2 K}$ & $V_{2 K}-0.5$ & $V_{2 K}+0.5$ \\
\hline & $S_{n}$ & $V_{n 1}$ & $V_{n 1}-0.5$ & $V_{n 1}+0.5$ & $\ldots$ & & $V_{n K}$ & $V_{n K}-0.5$ & $V_{n K}+0.5$ \\
\hline .. & & & & & $\cdots$ & & & t & $\cdots$ \\
\hline \multirow{5}{*}{$a_{7}$} & & 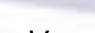 & & & & & & & \\
\hline & $S_{1}$ & $V_{11}$ & $V_{11}-0.5$ & $V_{11}+0.5$ & & & $V_{1 K}$ & $V_{1 K^{-0}} 0.5$ & $V_{1 K}+0.5$ \\
\hline & $S_{2}$ & $V_{21}$ & $V_{21}-0.5$ & $V_{21}+0.5$ & $\ldots$ & $\ldots$ & $V_{2 K}$ & $V_{2 K}-0.5$ & $V_{2 K}+0.5$ \\
\hline & $\cdots$ & $\cdots$ & $\cdots$ & $\cdots$ & $\ldots$ & $\ldots$ & $\ldots$ & $\ldots$ & $\ldots$ \\
\hline & $S_{n}$ & $V_{n 1}$ & $V_{n 1}-0.5$ & $V_{n 1}+0.5$ & $\ldots$ & $\ldots$ & $V_{n K}$ & $V_{n K}-0.5$ & $V_{n K+}+0.5$ \\
\hline
\end{tabular}

Table 3. Dummy attribute ratings chart

where $\mathrm{Vi}$ refers to the rating value of evaluation criteria from respondents' survey results and $\mathrm{K}$ is the number of group of respondents.

(ii) Determine the minimum value, $\underline{v}_{i j}$ and maximum value, $\bar{v}_{i j}$ using the following formula:

$$
\underline{v}_{i j}=\frac{1}{K}\left[v_{i j}{ }^{1} \operatorname{Min}+v_{i j}^{2} \operatorname{Min}+\ldots+v_{i j}{ }^{K}{ }_{\operatorname{Min}}\right]
$$




$$
\bar{v}_{i j}=\frac{1}{K}\left[v_{i j}{ }^{1} \operatorname{Max}+v_{i j}{ }^{2} \operatorname{Max}+\ldots+v_{i j}{ }^{K} \text { Max }\right]
$$

\section{Verification using Rough-Grey Analysis}

The Rough-Grey Analysis approach is very suitable for solving the group decision-making problem in an environment of uncertainty. The attribute ratings $\otimes v$ for benefit attributes are shown in Table 4 . The selection procedures are summarised as follows [44-46]:

Table 4. The scale of attribute ratings $\otimes v$ for benefit attributes

\begin{tabular}{|c|c|}
\hline Scale & $\square v$ \\
\hline Very poor (VP) & {$[0,1]$} \\
\hline Poor (P) & {$[1,3]$} \\
\hline Medium poor (MP) & {$[3,4]$} \\
\hline Fair (F) & {$[4,5]$} \\
\hline Medium good (MG) & {$[5,6]$} \\
\hline Good (G) & {$[6,9]$} \\
\hline Very good (VG) & {$[9,10]$} \\
\hline
\end{tabular}

(i) Establishment of grey decision table. Form a committee of DMs and determine attribute values of alternatives.

(ii) Normalisation of grey decision table.

(iii) Determination of the suitable alternatives. In order to reduce unnecessary information and maintain the determining rules, we determine the suitable alternatives by a grey-based rough set with lower approximation.

(iv) Making the ideal alternative for reference.

(v) Selection of the most suitable alternative. The grey relational grade (GRG) can be denoted as:

$$
\Gamma_{0 i}=\sum_{k-1}^{n} \frac{1}{n} \gamma\left(\otimes x_{0}(k), \otimes x_{i}(k)\right)
$$

where $\Gamma_{0 i}$ represents the degree of relation between each comparative sequence and the reference sequence and $\gamma\left(\otimes x_{0}(k), \otimes x_{i}(k)\right)$ is the grey relational coefficient $(\mathrm{GRC})$ of $\otimes x_{i}$ with respect to $\otimes x_{0}$ at the $k$ th attribute.

\section{IMPLEMENTATION}

\section{Implementation Strategy}

The details of the implementation of the proposed approach are depicted in Fig 2. Phase 1 is the formulation of the initial criteria and alternatives from secondary sources, the distribution of questionnaires to selected respondents and a summary of the survey results from the respondents. All of these processes are expected to be completed within a minimum three-month period based on previous record of the company. In phase 2, the HoQ method will be applied in selecting the criteria before executing the PCM operation and this process is expected to complete within three months.

In phase 3, in ideal conditions, the rank of alternatives obtained from phase 2 will be verified and validated using the Rough-Grey Analysis method without any iteration process and thus, indirectly reduce the development time. This process is expected to consume up to three months to complete. In total, the duration of completing the design evaluation using the newly proposed approach under ideal conditions is expected to be no more than nine months. As stated in previous paragraph, the expected duration of this development is based on previous development record of the company. The actual completion period will be measured within the proposed case study. 
Integration of Fuzzy-AHP with HoQ and Rough-Grey Analysis

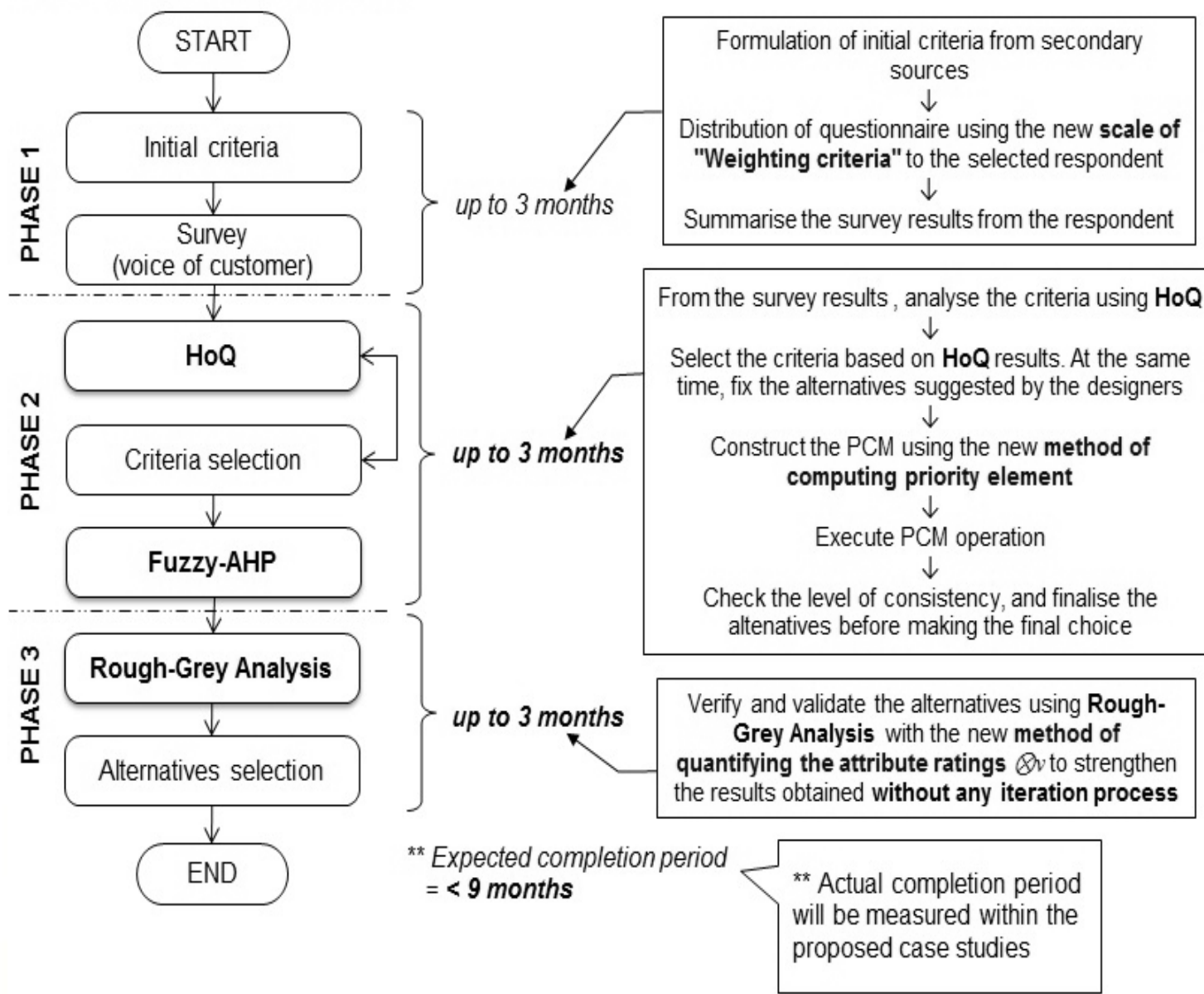

Fig 2: Implementation of proposed approach

\section{Case Study}

In the case study, the criteria and alternatives formulation will involve initial criteria selection from technical documents and survey results from questionnaires. The application is to select the best potentiometer design among six developed concept designs, which have been designed by the design engineers. These alternatives are depicted in Fig 3 . From the point of view of the design engineers, all six alternatives could potentially be manufactured. There are five decision makers whose views are deemed important and they should be taken into account for making a decision. They are the OEM customers, distributors, sales department, manufacturing department and top management group. The actual completion will be measured. 

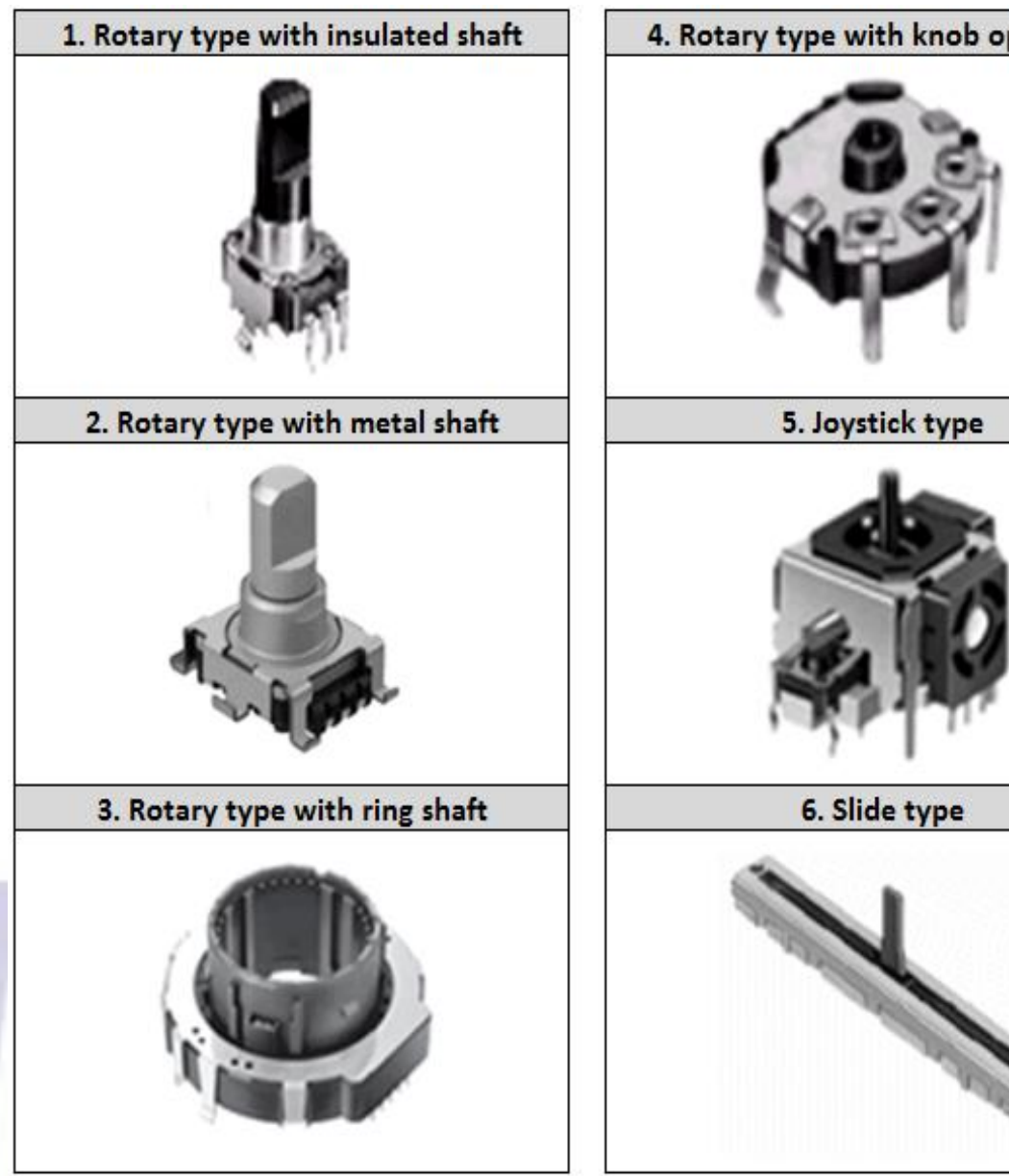

5. Joystick type

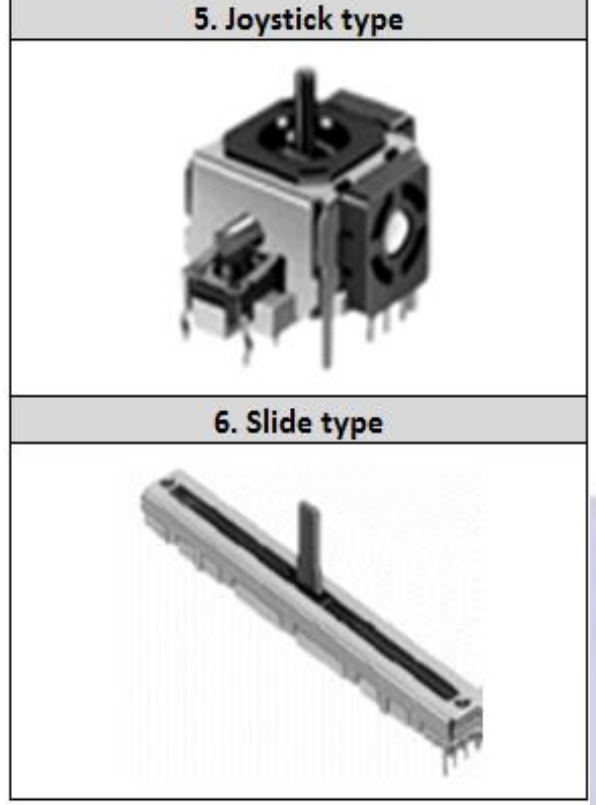

Fig 3: Design alternatives for the case study

Table 5 lists the initial criteria for the case study. The table describes the criteria in more detail. Initially, there are total of 32 criteria being selected by the design engineers based on technical documents and the results of a prior survey.

Table 5. Initial criteria for the case study

\begin{tabular}{|c|l|c|}
\hline No. & \multicolumn{1}{|c|}{ Voice of customers } & Relevant criteria \\
\hline 1 & Product's cost/price? & Cost \\
\hline 2 & Existing customer? Potential customer? & Materials \\
\hline 3 & Type of materials used to produce this product? & Quality and reliability \\
\hline 4 & Quality and reliability of the product? & Weight \\
\hline 5 & Product's weight? & Product life span \\
\hline 6 & Total life of the product? & Environmental \\
\hline 7 & Maintenance level in producing the product? \\
\hline 8 & Does the product fulfil world's environmental standard? & Disposal \\
\hline 9 & Disposal related to product assembly process? & Performance \\
\hline 10 & Product's performance? & Manufacturing facilities \\
\hline 11 & Facilities used in producing the product? & Aesthetics, appearance and finish \\
\hline 12 & Product's aesthetic? & Packing \\
\hline 13 & Packing style for finished products? & Size \\
\hline 14 & Product's size? & Standards and specifications \\
\hline 15 & Standards and specifications of product? & \\
\hline & & \\
\hline
\end{tabular}




\begin{tabular}{|c|c|c|}
\hline 16 & Is the product competitive? & Competition \\
\hline 17 & Does the product going through all required test? & Testing \\
\hline 18 & Is the process of producing this product reliable? & Processes \\
\hline 19 & Storage of finished products? & Shelf life (storage) \\
\hline 20 & Quantity of each lot/batch? & Quantity \\
\hline 21 & Product's service life? & Life in service \\
\hline 22 & Safety level in producing the product? & Safety \\
\hline 23 & Is there any patent conflict? & Patent, literature and product data \\
\hline 24 & Internal constraints? & Company constraints \\
\hline 25 & Shipment condition? & Shipment \\
\hline 26 & Is the documentation available/completed? & Documentation \\
\hline 27 & External constraints? & Market constraints \\
\hline 28 & Is the process comfortable (human factors)? & Ergonomics \\
\hline 29 & Time consuming? & Time-scales \\
\hline 30 & Product's installation into the counter part? & Installation \\
\hline 31 & Follow the procedure/legal aspect? & Legal \\
\hline 32 & Any effect from political and social issue? & Political and social implications \\
\hline
\end{tabular}

\section{RESULTS AND ANALYSIS}

\section{Results}

\section{Survey Results}

Table 6 depicts the survey results for the case study using the proposed scale of "Weighting criteria". 
Table 6. Survey results of "Weighting criteria" for the case study

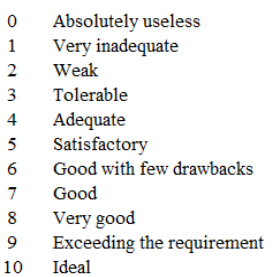

\begin{tabular}{|c|c|c|c|c|c|c|c|c|c|c|c|c|c|c|c|c|c|c|c|c|c|c|c|c|c|c|c|c|c|c|c|}
\hline \multirow{2}{*}{\multicolumn{2}{|c|}{ Evaluation criteria }} & \multicolumn{6}{|c|}{$O E M$} & \multicolumn{6}{|c|}{ Distributor } & \multicolumn{6}{|c|}{ Sales } & \multicolumn{6}{|c|}{ Top management } & \multicolumn{6}{|c|}{ Manufacturing } \\
\hline & & $\# 1$ & $\# 2$ & $\# 3$ & $\# 4$ & $\# 5$ & $\# 6$ & $\# 1$ & $\# 2$ & $\# 3$ & $\# 4$ & $\# 5$ & $\# 6$ & $\# 1$ & $\# 2$ & $\# 3$ & $\# 4$ & $\# 5$ & $\# 6$ & $\# 1$ & $\# 2$ & $\# 3$ & $\# 4$ & $\# 5$ & $\# 6$ & $\# 1$ & $\# 2$ & $\# 3$ & $\# 4$ & $\# 5$ & $\# 6$ \\
\hline 1 & Cost & 7 & 7 & 4 & 5 & 4 & 6 & 7 & 7 & 4 & 5 & 4 & 6 & 7 & 7 & 4 & 5 & 4 & 6 & 7 & 6 & 4 & 5 & 4 & 6 & 7 & 6 & 4 & 5 & 4 & 6 \\
\hline 2 & Customer & 7 & 7 & 4 & 5 & 4 & 5 & 7 & 7 & 4 & 5 & 4 & 5 & 7 & 7 & 4 & 5 & 4 & 5 & 7 & 7 & 4 & 5 & 4 & 5 & 7 & 7 & 5 & 5 & 4 & 5 \\
\hline 3 & Materials & 5 & 5 & 5 & 5 & 3 & 5 & 5 & 5 & 5 & 6 & 3 & 5 & 5 & 5 & 5 & 5 & 3 & 5 & 5 & 5 & 5 & 5 & 4 & 5 & 5 & 5 & 5 & 5 & 4 & 5 \\
\hline 4 & Quality and reliability & 5 & 5 & 5 & 5 & 3 & 5 & 5 & 5 & 5 & 5 & 3 & 5 & 3 & 3 & 3 & 3 & 2 & 3 & 5 & 5 & 5 & 5 & 4 & 5 & 5 & 5 & 5 & 5 & 4 & 5 \\
\hline 5 & Weight & 5 & 5 & 5 & 5 & 3 & 5 & 5 & 5 & 5 & 5 & 3 & 5 & 3 & 3 & 3 & 3 & 2 & 3 & 5 & 5 & 5 & 5 & 4 & 5 & 5 & 5 & 5 & 5 & 4 & 5 \\
\hline 6 & Product life sp & 4 & 4 & 4 & 4 & 3 & 4 & 4 & 4 & 4 & 4 & 3 & 4 & 4 & 4 & 4 & 4 & 3 & 4 & 4 & 4 & 4 & 4 & 3 & 4 & 5 & 5 & 5 & 5 & 4 & 5 \\
\hline 7 & Maintenance & 4 & 4 & 4 & 4 & 3 & 4 & 4 & 4 & 4 & 4 & 3 & 4 & 4 & 4 & 4 & 4 & 3 & 4 & 4 & 4 & 4 & 4 & 3 & 4 & 5 & 5 & 5 & 5 & 4 & 5 \\
\hline 8 & Environmental & 4 & 4 & 4 & 4 & 3 & 4 & 4 & 4 & 4 & 4 & 3 & 4 & 4 & 4 & 4 & 4 & 3 & 4 & 4 & 4 & 4 & 4 & 3 & 4 & 5 & 5 & 5 & 5 & 4 & 5 \\
\hline 9 & Disposal & 4 & 4 & 4 & 4 & 3 & 4 & 4 & 4 & 4 & 4 & 3 & 4 & 4 & 4 & 4 & 4 & 3 & 4 & 4 & 4 & 4 & 4 & 3 & 4 & 5 & 5 & 5 & 5 & 4 & 5 \\
\hline 10 & Performance & 4 & 4 & 4 & 4 & 3 & 4 & 4 & 4 & 4 & 4 & 3 & 4 & 4 & 4 & 4 & 4 & 3 & 4 & 4 & 4 & 4 & 4 & 3 & 4 & 5 & 5 & 5 & 5 & 4 & 5 \\
\hline 11 & Manufacturing facilities & 4 & 4 & 4 & 4 & 3 & 4 & 4 & 4 & 4 & 4 & 3 & 4 & 4 & 4 & 4 & 4 & 3 & 4 & 4 & 4 & 4 & 4 & 3 & 4 & 5 & 5 & 5 & 5 & 4 & 5 \\
\hline 12 & Aesthetics, appearance and finish & 4 & 4 & 4 & 4 & 3 & 4 & 4 & 4 & 4 & 4 & 3 & 4 & 4 & 4 & 4 & 4 & 3 & 4 & 4 & 4 & 4 & 4 & 3 & 4 & 5 & 5 & 5 & 5 & 4 & 5 \\
\hline 13 & Packing & 3 & 3 & 3 & 3 & 3 & 3 & 3 & 3 & 3 & 3 & 3 & 3 & 3 & 3 & 3 & 3 & 3 & 3 & 3 & 3 & 3 & 3 & 3 & 3 & 3 & 3 & 3 & 3 & 3 & 3 \\
\hline 14 & Size & 4 & 4 & 4 & 4 & 3 & 4 & 4 & 4 & 4 & 4 & 3 & 4 & 4 & 4 & 4 & 4 & 3 & 4 & 4 & 4 & 4 & 4 & 3 & 4 & 5 & 5 & 5 & 5 & 4 & 5 \\
\hline 15 & Standards and specifications & 4 & 4 & 4 & 4 & 3 & 4 & 4 & 4 & 4 & 4 & 3 & 4 & 4 & 4 & 4 & 4 & 3 & 4 & 4 & 4 & 4 & 4 & 3 & 4 & 5 & 5 & 5 & 5 & 4 & 5 \\
\hline 16 & Competition & 4 & 4 & 4 & 4 & 3 & 4 & 4 & 4 & 4 & 4 & 3 & 4 & 4 & 4 & 4 & 4 & 3 & 4 & 4 & 4 & 4 & 4 & 3 & 4 & 5 & 5 & 5 & 5 & 4 & 5 \\
\hline 17 & Testing & 3 & 3 & 3 & 3 & 3 & 3 & 3 & 3 & 3 & 3 & 3 & 3 & 3 & 3 & 3 & 3 & 3 & 3 & 3 & 3 & 3 & 3 & 3 & 3 & 3 & 3 & 3 & 3 & 3 & 3 \\
\hline 18 & Processes & 3 & 3 & 3 & 3 & 3 & 3 & 3 & 3 & 3 & 3 & 3 & 3 & 3 & 3 & 3 & 3 & 3 & 3 & 3 & 3 & 3 & 3 & 3 & 3 & 3 & 3 & 3 & 3 & 3 & 3 \\
\hline 19 & Shelf life (storage) & 3 & 3 & 3 & 3 & 3 & 3 & 3 & 3 & 3 & 3 & 3 & 3 & 3 & 3 & 3 & 3 & 3 & 3 & 3 & 3 & 3 & 3 & 3 & 3 & 3 & 3 & 3 & 3 & 3 & 3 \\
\hline 20 & Quantity & 3 & 3 & 3 & 3 & 3 & 3 & 3 & 3 & 3 & 3 & 3 & 3 & 3 & 3 & 3 & 3 & 3 & 3 & 3 & 3 & 3 & 3 & 3 & 3 & 3 & 3 & 3 & 3 & 3 & 3 \\
\hline 21 & Life in service & 3 & 3 & 3 & 3 & 3 & 3 & 3 & 3 & 3 & 3 & 3 & 3 & 3 & 3 & 3 & 3 & 3 & 3 & 3 & 3 & 3 & 3 & 3 & 3 & 3 & 3 & 3 & 3 & 3 & 3 \\
\hline 22 & Safety & 4 & 4 & 4 & 4 & 3 & 4 & 4 & 4 & 4 & 4 & 3 & 4 & 4 & 4 & 4 & 4 & 3 & 4 & 4 & 4 & 4 & 4 & 3 & 4 & 5 & 5 & 5 & 5 & 4 & 5 \\
\hline 23 & Patent, literature and pr & 4 & 4 & 4 & 4 & 3 & 4 & 4 & 4 & 4 & 4 & 3 & 4 & 4 & 4 & 4 & 4 & 3 & 4 & 4 & 4 & 4 & 4 & 3 & 4 & 5 & 5 & 5 & 5 & 4 & 5 \\
\hline 24 & Company constraints & 3 & 3 & 3 & 3 & 3 & 3 & 3 & 3 & 3 & 3 & 3 & 3 & 3 & 3 & 3 & 3 & 3 & 3 & 3 & 3 & 3 & 3 & 3 & 3 & 3 & 3 & 3 & 3 & 3 & 3 \\
\hline 25 & Shipment & 3 & 3 & 3 & 3 & 3 & 3 & 3 & 3 & 3 & 3 & 3 & 3 & 3 & 3 & 3 & 3 & 3 & 3 & 3 & 3 & 3 & 3 & 3 & 3 & 3 & 3 & 3 & 3 & 3 & 3 \\
\hline 26 & Documentation & 3 & 3 & 3 & 3 & 3 & 3 & 3 & 3 & 3 & 3 & 3 & 3 & 3 & 3 & 3 & 3 & 3 & 3 & 3 & 3 & 3 & 3 & 3 & 3 & 3 & 3 & 3 & 3 & 3 & 3 \\
\hline 27 & Market constraints & 3 & 3 & 3 & 3 & 3 & 3 & 3 & 3 & 3 & 3 & 3 & 3 & 3 & 3 & 3 & 3 & 3 & 3 & 3 & 3 & 3 & 3 & 3 & 3 & 3 & 3 & 3 & 3 & 3 & 3 \\
\hline 28 & Ergonomics & 3 & 3 & 3 & 3 & 3 & 3 & 3 & 3 & 3 & 3 & 3 & 3 & 3 & 3 & 3 & 3 & 3 & 3 & 3 & 3 & 3 & 3 & 3 & 3 & 3 & 3 & 3 & 3 & 3 & 3 \\
\hline 29 & Time-scales & 3 & 3 & 3 & 3 & 3 & 3 & 3 & 3 & 3 & 3 & 3 & 3 & 3 & 3 & 3 & 3 & 3 & 3 & 3 & 3 & 3 & 3 & 3 & 3 & 3 & 3 & 3 & 3 & 3 & 3 \\
\hline 30 & Installation & 3 & 3 & 3 & 3 & 3 & 3 & 3 & 3 & 3 & 3 & 3 & 3 & 3 & 3 & 3 & 3 & 3 & 3 & 3 & 3 & 3 & 3 & 3 & 3 & 3 & 3 & 3 & 3 & 3 & 3 \\
\hline 31 & Legal & 3 & 3 & 3 & 3 & 3 & 3 & 3 & 3 & 3 & 3 & 3 & 3 & 3 & 3 & 3 & 3 & 3 & 3 & 3 & 3 & 3 & 3 & 3 & 3 & 3 & 3 & 3 & 3 & 3 & 3 \\
\hline 32 & Political and social implications & 3 & 3 & 3 & 3 & 3 & 3 & 3 & 3 & 3 & 3 & 3 & 3 & 3 & 3 & 3 & 3 & 3 & 3 & 3 & 3 & 3 & 3 & 3 & 3 & 3 & 3 & 3 & 3 & 3 & 3 \\
\hline & Total & 122 & 122 & 116 & 118 & 98 & 119 & 122 & 122 & 116 & 119 & 98 & 119 & 118 & 118 & 112 & 114 & 96 & 115 & 122 & 121 & 116 & 118 & 101 & 119 & 134 & 133 & 129 & 130 & 113 & 131 \\
\hline
\end{tabular}

\section{Screening using HoQ}

The process explained in the previous section was followed in utilising the HoQ for the screening process of the case study. Then, experts in the multidisciplinary team identified the relationships between each pair of customer's requirements and the technical requirements. HoQ matrix for the case study was not included due to the company are not agreed to disclose the customer attributes data. However, they have gave the consent to display the technical requirements for purpose of showing analysis results. The output from the HoQ matrix, which is the HoQ summary, is shown in Table 7. The summary of $\mathrm{HoQ}$ includes the relative weight or relative importance of each quality characteristic. The weight obtained will be ranked, filtered and used as a reference for the next process. Table 8 is the modified HoQ summary after the selection of the top seven criteria.

Table 7. HoQ summary for the case study

\begin{tabular}{|c|c|c|c|c|}
\hline $\begin{array}{c}\text { Row } \\
\text { Number }\end{array}$ & $\begin{array}{c}\text { Quality Characteristics } \\
\text { (a.k.a. "Functional Requirements" } \\
\text { or "Hows") }\end{array}$ & $\begin{array}{l}\text { Minimise }(\nabla) \text {, } \\
\text { Maximise }(\mathbf{\Delta}) \text {, } \\
\text { or Target }(\mathbf{x})\end{array}$ & $\begin{array}{l}\text { Requirement } \\
\text { Weight }\end{array}$ & $\begin{array}{c}\text { Relative } \\
\text { Weight } \\
\text { (Relative } \\
\text { Importance) }\end{array}$ \\
\hline 1 & Cost & $\nabla$ & 420.83 & $5.03 \%$ \\
\hline 2 & Customer & $\bar{\Delta}$ & 395.73 & $4.73 \%$ \\
\hline 3 & Materials & $\nabla$ & 358.62 & $4.28 \%$ \\
\hline 4 & Quality and reliability & $\bar{\Delta}$ & 347.14 & $4.15 \%$ \\
\hline 5 & Weight & $\nabla$ & 338.66 & $4.04 \%$ \\
\hline 6 & Product life span & $\overline{\mathbf{\Delta}}$ & 322.25 & $3.85 \%$ \\
\hline 7 & Maintenance & $\boldsymbol{\nabla}$ & 315.06 & $3.76 \%$ \\
\hline
\end{tabular}




\begin{tabular}{|c|c|c|c|c|}
\hline 8 & Environmental & $\boldsymbol{\Delta}$ & 303.55 & $3.63 \%$ \\
\hline 9 & Disposal & $\boldsymbol{\nabla}$ & 302.89 & $3.62 \%$ \\
\hline 10 & Performance & $\Delta$ & 301.97 & $3.61 \%$ \\
\hline 11 & Manufacturing facilities & $\boldsymbol{\Delta}$ & 301.85 & $3.60 \%$ \\
\hline 12 & Aesthetics, appearance and finish & $\boldsymbol{\Delta}$ & 293.70 & $3.51 \%$ \\
\hline 13 & Packing & $\mathrm{x}$ & 279.25 & $3.33 \%$ \\
\hline 14 & Size & $\boldsymbol{\nabla}$ & 275.28 & $3.29 \%$ \\
\hline 15 & Standards and specifications & $\boldsymbol{\Delta}$ & 265.64 & $3.17 \%$ \\
\hline 16 & Competition & $\boldsymbol{\Delta}$ & 263.07 & $3.14 \%$ \\
\hline 17 & Testing & $\Delta$ & 259.79 & $3.10 \%$ \\
\hline 18 & Processes & $\boldsymbol{\nabla}$ & 256.75 & $3.07 \%$ \\
\hline 19 & Shelf life (storage) & $\boldsymbol{\Delta}$ & 242.73 & $2.90 \%$ \\
\hline 20 & Quantity & $\boldsymbol{\Delta}$ & 234.60 & $2.80 \%$ \\
\hline 21 & Life in service & $\boldsymbol{\Delta}$ & 222.35 & $2.66 \%$ \\
\hline 22 & Safety & $\boldsymbol{\Delta}$ & 218.46 & $2.61 \%$ \\
\hline 23 & Patent, literature and product data & $\mathrm{x}$ & 216.93 & $2.59 \%$ \\
\hline 24 & Company constraints & $\boldsymbol{\nabla}$ & 214.44 & $2.56 \%$ \\
\hline 25 & Shipment & $\Delta$ & 209.86 & $2.51 \%$ \\
\hline 26 & Documentation & $\boldsymbol{\nabla}$ & 208.16 & $2.49 \%$ \\
\hline 27 & Market constraints & $\boldsymbol{\nabla}$ & 204.22 & $2.44 \%$ \\
\hline 28 & Ergonomics & $\boldsymbol{\Delta}$ & 183.82 & $2.20 \%$ \\
\hline 29 & Time-scales & $\nabla$ & 170.60 & $2.04 \%$ \\
\hline 30 & Installation & $\Delta$ & 168.74 & $2.02 \%$ \\
\hline 31 & Legal & $\mathrm{x}$ & 144.35 & $1.72 \%$ \\
\hline 32 & Political and social implications & $\boldsymbol{\nabla}$ & 132.41 & $1.58 \%$ \\
\hline
\end{tabular}

Table 8. Modified HoQ summary for the case study

\begin{tabular}{|c|c|c|c|c|}
\hline $\begin{array}{c}\text { Row } \\
\text { Number }\end{array}$ & $\begin{array}{c}\text { Quality Characteristics } \\
\text { (a.k.a. "Functional Requirements" } \\
\text { or "Hows") }\end{array}$ & $\begin{array}{l}\text { Minimise }(\nabla) \text {, } \\
\text { Maximise }(\mathbf{\Delta}) \text {, } \\
\text { or Target }(\mathbf{x})\end{array}$ & $\begin{array}{l}\text { Requirement } \\
\text { Weight }\end{array}$ & $\begin{array}{c}\text { Relative } \\
\text { Weight } \\
\text { (Relative } \\
\text { Importance) }\end{array}$ \\
\hline 1 & Cost & $\nabla$ & 420.83 & $16.84 \%$ \\
\hline 2 & Customer & $\boldsymbol{\Delta}$ & 395.73 & $15.84 \%$ \\
\hline 3 & Materials & $\nabla$ & 358.62 & $14.35 \%$ \\
\hline 4 & Quality and reliability & $\boldsymbol{\Delta}$ & 347.14 & $13.90 \%$ \\
\hline 5 & Weight & $\nabla$ & 338.66 & $13.56 \%$ \\
\hline 6 & Product life span & $\boldsymbol{\Delta}$ & 322.25 & $12.90 \%$ \\
\hline 7 & Maintenance & $\boldsymbol{\nabla}$ & 315.06 & $12.61 \%$ \\
\hline
\end{tabular}

\section{Computing the priority of element}

Table 9 depicts the dummy evaluation chart for all top seven criteria which will help the designers to construct the PCM after computing the priority of element using the new method. 
Table 9. Dummy evaluation chart for the case study

\begin{tabular}{llllll}
\hline \multicolumn{7}{c}{ Criteria 1 } \\
\hline 1.18 & 1.11 & 0.67 & 0.84 & 0.67 & 1.01 \\
\hline 1.00 & 1.06 & 1.75 & 1.40 & 1.75 & 1.17 \\
0.94 & 1.00 & 0.61 & 0.76 & 0.61 & 0.91 \\
0.57 & 1.65 & 1.00 & 0.80 & 1.00 & 0.67 \\
0.71 & 1.32 & 1.25 & 1.00 & 0.80 & 1.20 \\
0.57 & 1.65 & 1.00 & 1.25 & 1.00 & 0.67 \\
0.86 & 1.10 & 1.50 & 0.83 & 1.50 & 1.00 \\
\hline \hline
\end{tabular}

\begin{tabular}{cccccc}
\hline \multicolumn{7}{c}{ Criteria 2} \\
\hline 1.11 & 1.11 & 0.67 & 0.79 & 0.63 & 0.79 \\
\hline 1.00 & 1.00 & 1.67 & 1.40 & 1.75 & 1.40 \\
1.00 & 1.00 & 0.60 & 0.71 & 0.57 & 0.71 \\
0.60 & 1.67 & 1.00 & 0.84 & 1.05 & 0.84 \\
0.71 & 1.40 & 1.19 & 1.00 & 0.80 & 1.00 \\
0.57 & 1.75 & 0.95 & 1.25 & 1.00 & 0.80 \\
0.71 & 1.40 & 1.19 & 1.00 & 1.25 & 1.00 \\
\hline \hline \multicolumn{6}{c}{ Criteria 4} \\
\hline 0.64 & 0.64 & 0.64 & 0.64 & 0.44 & 0.64 \\
\hline 1.00 & 1.00 & 1.00 & 1.00 & 1.44 & 1.00 \\
1.00 & 1.00 & 1.00 & 1.00 & 0.70 & 1.00 \\
1.00 & 1.00 & 1.00 & 1.00 & 1.44 & 1.00 \\
1.00 & 1.00 & 1.00 & 1.00 & 0.70 & 1.00 \\
0.70 & 1.44 & 0.70 & 1.44 & 1.00 & 0.70 \\
1.00 & 1.00 & 1.00 & 1.00 & 1.44 & 1.00 \\
\hline \hline \multicolumn{6}{c}{ Criteria 6} \\
\hline 0.54 & 0.54 & 0.54 & 0.54 & 0.41 & 0.54 \\
\hline 1.00 & 1.00 & 1.00 & 1.00 & 1.31 & 1.00 \\
1.00 & 1.00 & 1.00 & 1.00 & 0.76 & 1.00 \\
1.00 & 1.00 & 1.00 & 1.00 & 1.31 & 1.00 \\
1.00 & 1.00 & 1.00 & 1.00 & 0.76 & 1.00 \\
0.76 & 1.31 & 0.76 & 1.31 & 1.00 & 0.76 \\
1.00 & 1.00 & 1.00 & 1.00 & 1.31 & 1.00 \\
\hline
\end{tabular}

\begin{tabular}{llll}
1.00 & 1.00 & 1.00 & 1.00 \\
\hline & Criteria
\end{tabular}

\begin{tabular}{llllll}
\hline 0.53 & 0.53 & 0.53 & 0.53 & 0.40 & 0.53 \\
\hline 1.00 & 1.00 & 1.00 & 1.00 & 1.31 & 1.00 \\
1.00 & 1.00 & 1.00 & 1.00 & 0.76 & 1.00 \\
1.00 & 1.00 & 1.00 & 1.00 & 1.31 & 1.00 \\
1.00 & 1.00 & 1.00 & 1.00 & 0.76 & 1.00 \\
0.76 & 1.31 & 0.76 & 1.31 & 1.00 & 0.76 \\
1.00 & 1.00 & 1.00 & 1.00 & 1.31 & 1.00 \\
\hline
\end{tabular}

\section{Evaluation using Fuzzy-AHP}

Fig 4 depicts the hierarchical structure of alternatives and general criteria to prioritise alternatives for selecting the best potentiometer design in the case of applying $\mathrm{HoQ}_{\mathrm{O}}$ as a screening process. The criteria $\left(U_{i}\right)$ represent a combination of strategic index and key factors in the design selection based on the screening results obtained from the previous process. At the next level, six alternatives as suggested by the designers were considered that influence the criteria significantly.

Goal Criteria Alternatives

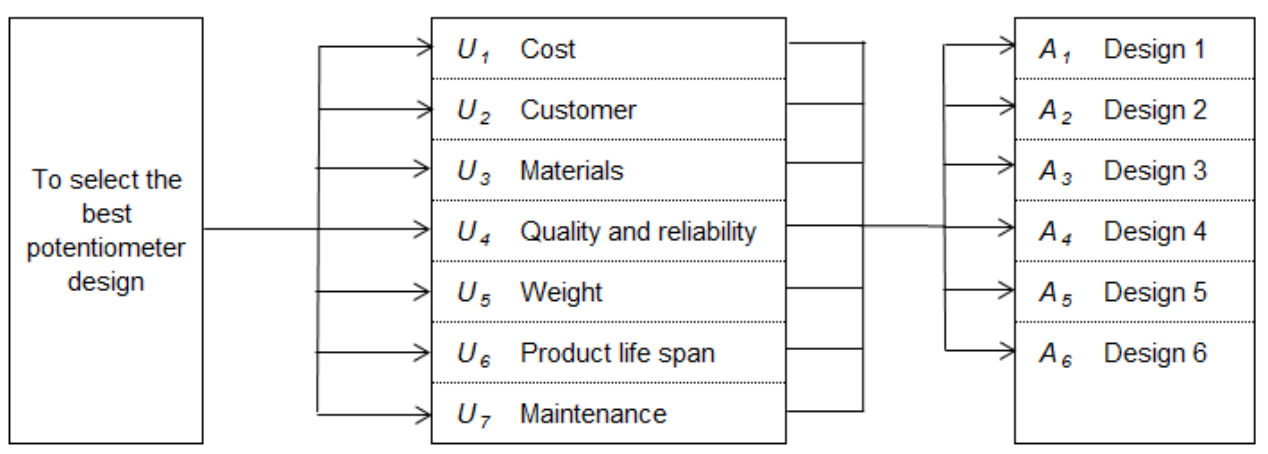

Fig 4: Analytic hierarchy structure for the case study 
Fig 5 illustrates a subset of alternative PCMs and Fig 6 presents the results of the prioritisation weights calculations for the alternatives with respect to the criteria for the proposed approach.

\begin{tabular}{|c|c|c|c|c|c|c|}
\hline & $\begin{array}{l}\mathbf{U}_{\mathbf{l}} \\
\mathrm{A}_{1}\end{array}$ & $\begin{array}{r}\text { Cost } \\
\mathrm{A}_{2}\end{array}$ & $\mathrm{~A}_{3}$ & $\mathrm{~A}_{4}$ & $\mathrm{~A}_{5}$ & $A_{6}$ \\
\hline$A_{1}$ & 1.00 & 1.06 & 1.75 & 1.40 & 1.75 & 1.17 \\
\hline $\mathrm{A}_{2}$ & 0.94 & 1.00 & 0.61 & 0.76 & 0.61 & 0.91 \\
\hline $\mathrm{A}_{3}$ & 0.57 & 1.65 & 1.00 & 0.80 & 1.00 & 0.67 \\
\hline $\mathrm{A}_{4}$ & 0.71 & 1.32 & 1.25 & 1.00 & 0.80 & 1.20 \\
\hline$A_{5}$ & 0.57 & 1.65 & 1.00 & 1.25 & 1.00 & 0.67 \\
\hline$A_{6}$ & 0.86 & 1.10 & 1.50 & 0.83 & 1.50 & 1.00 \\
\hline
\end{tabular}

\begin{tabular}{l|cccccc|}
\multicolumn{2}{c}{$\mathbf{U}_{5}$} & \multicolumn{2}{c}{ Weight } & & & \\
\multicolumn{1}{c}{} & $\mathrm{A}_{1}$ & $\mathrm{~A}_{2}$ & $\mathrm{~A}_{3}$ & $\mathrm{~A}_{4}$ & $\mathrm{~A}_{5}$ & $\mathrm{~A}_{6}$ \\
\cline { 2 - 7 } $\mathrm{A}_{1}$ & 1.00 & 1.00 & 1.00 & 1.00 & 1.44 & 1.00 \\
$\mathrm{~A}_{2}$ & 1.00 & 1.00 & 1.00 & 1.00 & 0.70 & 1.00 \\
$\mathrm{~A}_{3}$ & 1.00 & 1.00 & 1.00 & 1.00 & 1.44 & 1.00 \\
$\mathrm{~A}_{4}$ & 1.00 & 1.00 & 1.00 & 1.00 & 0.70 & 1.00 \\
$\mathrm{~A}_{5}$ & 0.70 & 1.44 & 0.70 & 1.44 & 1.00 & 0.70 \\
$\mathrm{~A}_{6}$ & 1.00 & 1.00 & 1.00 & 1.00 & 1.44 & 1.00 \\
\cline { 2 - 6 } & & & & & &
\end{tabular}

\section{$\mathrm{U}_{2}$ Customer}

\begin{tabular}{l|cccccc|}
\multicolumn{1}{c}{} & $\mathrm{A}_{1}$ & $\mathrm{~A}_{2}$ & $\mathrm{~A}_{3}$ & $\mathrm{~A}_{4}$ & $\mathrm{~A}_{5}$ & $\mathrm{~A}_{6}$ \\
\cline { 2 - 7 } $\mathrm{A}_{1}$ & 1.00 & 1.00 & 1.67 & 1.40 & 1.75 & 1.40 \\
$\mathrm{~A}_{2}$ & 1.00 & 1.00 & 0.60 & 0.71 & 0.57 & 0.71 \\
$\mathrm{~A}_{3}$ & 0.60 & 1.67 & 1.00 & 0.84 & 1.05 & 0.84 \\
$\mathrm{~A}_{4}$ & 0.71 & 1.40 & 1.19 & 1.00 & 0.80 & 1.00 \\
$\mathrm{~A}_{5}$ & 0.57 & 1.75 & 0.95 & 1.25 & 1.00 & 0.80 \\
$\mathrm{~A}_{6}$ & 0.71 & 1.40 & 1.19 & 1.00 & 1.25 & 1.00 \\
\cline { 2 - 7 } & & & & & &
\end{tabular}

\begin{tabular}{|c|c|c|c|c|c|c|}
\hline & $A_{1}$ & $\mathrm{~A}_{2}$ & $\mathrm{~A}_{3}$ & $\mathrm{~A}_{4}$ & $\mathrm{~A}_{5}$ & $A_{6}$ \\
\hline & 1.00 & 1.00 & 1.00 & 1.00 & 1.31 & 1.00 \\
\hline & 00 & 1.00 & 1.00 & 1.00 & 0.76 & 1.00 \\
\hline & 0 & 1 & 1 & 1.00 & 31 & .00 \\
\hline & 0 & 1 & 1.00 & 1.00 & .76 & 1.00 \\
\hline & .76 & 1.31 & 0.76 & 1.31 & 1.00 & 0.76 \\
\hline & 1.00 & 1.00 & 1.00 & 1.00 & 1.31 & 1.00 \\
\hline
\end{tabular}

$\mathrm{U}_{3}$ Materials

\begin{tabular}{l|cccccc|}
\multicolumn{1}{c}{} & $\mathrm{A}_{1}$ & $\mathrm{~A}_{2}$ & $\mathrm{~A}_{3}$ & $\mathrm{~A}_{4}$ & $\mathrm{~A}_{5}$ & $\mathrm{~A}_{6}$ \\
\cline { 2 - 7 } $\mathrm{A}_{1}$ & 1.00 & 1.00 & 1.00 & 0.96 & 1.47 & 1.00 \\
$\mathrm{~A}_{2}$ & 1.00 & 1.00 & 1.00 & 1.04 & 0.68 & 1.00 \\
$\mathrm{~A}_{3}$ & 1.00 & 1.00 & 1.00 & 0.96 & 1.47 & 1.00 \\
$\mathrm{~A}_{4}$ & 1.04 & 0.96 & 1.04 & 1.00 & 0.65 & 0.96 \\
$\mathrm{~A}_{5}$ & 0.68 & 1.47 & 0.68 & 1.53 & 1.00 & 0.68 \\
$\mathrm{~A}_{6}$ & 1.00 & 1.00 & 1.00 & 1.04 & 1.47 & 1.00 \\
\cline { 2 - 6 } & & & & & &
\end{tabular}

$\mathrm{U}_{4}$ Quality and reliability

\begin{tabular}{l|cccccc|}
\multicolumn{1}{c}{} & $\mathrm{A}_{1}$ & $\mathrm{~A}_{2}$ & $\mathrm{~A}_{3}$ & $\mathrm{~A}_{4}$ & $\mathrm{~A}_{5}$ & $\mathrm{~A}_{6}$ \\
\cline { 2 - 7 } $\mathrm{A}_{1}$ & 1.00 & 1.00 & 1.00 & 1.00 & 1.44 & 1.00 \\
$\mathrm{~A}_{2}$ & 1.00 & 1.00 & 1.00 & 1.00 & 0.70 & 1.00 \\
$\mathrm{~A}_{3}$ & 1.00 & 1.00 & 1.00 & 1.00 & 1.44 & 1.00 \\
$\mathrm{~A}_{4}$ & 1.00 & 1.00 & 1.00 & 1.00 & 0.70 & 1.00 \\
$\mathrm{~A}_{5}$ & 0.70 & 1.44 & 0.70 & 1.44 & 1.00 & 0.70 \\
$\mathrm{~A}_{6}$ & 1.00 & 1.00 & 1.00 & 1.00 & 1.44 & 1.00 \\
\cline { 2 - 6 } & & & &
\end{tabular}

\section{$\mathrm{U}_{7} \quad$ Maintenance}

\begin{tabular}{l|cccccc|}
\multicolumn{1}{c}{} & $\mathrm{A}_{1}$ & $\mathrm{~A}_{2}$ & $\mathrm{~A}_{3}$ & $\mathrm{~A}_{4}$ & $\mathrm{~A}_{5}$ & $\mathrm{~A}_{6}$ \\
\cline { 2 - 7 } $\mathrm{A}_{1}$ & 1.00 & 1.00 & 1.00 & 1.00 & 1.31 & 1.00 \\
$\mathrm{~A}_{2}$ & 1.00 & 1.00 & 1.00 & 1.00 & 0.76 & 1.00 \\
$\mathrm{~A}_{3}$ & 1.00 & 1.00 & 1.00 & 1.00 & 1.31 & 1.00 \\
$\mathrm{~A}_{4}$ & 1.00 & 1.00 & 1.00 & 1.00 & 0.76 & 1.00 \\
$\mathrm{~A}_{5}$ & 0.76 & 1.31 & 0.76 & 1.31 & 1.00 & 0.76 \\
$\mathrm{~A}_{6}$ & 1.00 & 1.00 & 1.00 & 1.00 & 1.31 & 1.00 \\
\cline { 2 - 6 }
\end{tabular}

Fig 5: Fuzzy pair-wise comparison matrices for alternatives for the case study 


\begin{tabular}{|c|c|c|c|c|c|c|c|c|c|c|}
\hline$U_{1}$ & Cost & $A_{1}$ & $\mathrm{~A}_{2}$ & $A_{3}$ & $\mathrm{~A}_{4}$ & $A_{5}$ & $\mathrm{~A}_{6}$ & $w_{A k}$ & & \\
\hline & $A_{1}$ & 1.000 & 1.061 & 1.750 & 1.400 & 1.750 & 1.167 & 0.215 & $\lambda_{\max }$ & 6.478 \\
\hline & $\mathrm{A}_{2}$ & 0.943 & 1.000 & 0.606 & 0.758 & 0.606 & 0.909 & 0.202 & C.I. & 0.096 \\
\hline & $\mathrm{A}_{3}$ & 0.571 & 1.650 & 1.000 & 0.800 & 1.000 & 0.667 & 0.123 & C.R. & 0.077 \\
\hline & $\mathrm{A}_{4}$ & 0.714 & 1.320 & 1.250 & 1.000 & 0.800 & 1.200 & 0.153 & & \\
\hline & $A_{5}$ & 0.571 & 1.650 & 1.000 & 1.250 & 1.000 & 0.667 & 0.123 & & \\
\hline & $\mathrm{A}_{6}$ & 0.857 & 1.100 & 1.500 & 0.833 & 1.500 & 1.000 & 0.184 & & \\
\hline \multirow[t]{7}{*}{$U_{2}$} & Customer & $A_{1}$ & $\mathrm{~A}_{2}$ & $A_{3}$ & $\mathrm{~A}_{4}$ & $A_{5}$ & $\mathrm{~A}_{6}$ & $w_{A k}$ & & \\
\hline & $A_{1}$ & 1.000 & 1.000 & 1.667 & 1.400 & 1.750 & 1.400 & 0.217 & $\lambda_{\max }$ & 6.612 \\
\hline & $\mathrm{A}_{2}$ & 1.000 & 1.000 & 0.600 & 0.714 & 0.571 & 0.714 & 0.217 & C.I. & 0.122 \\
\hline & $A_{3}$ & 0.600 & 1.667 & 1.000 & 0.840 & 1.050 & 0.840 & 0.130 & C.R. & 0.098 \\
\hline & $\mathrm{A}_{4}$ & 0.714 & 1.400 & 1.190 & 1.000 & 0.800 & 1.000 & 0.155 & & \\
\hline & $A_{5}$ & 0.571 & 1.750 & 0.952 & 1.250 & 1.000 & 0.800 & 0.124 & & \\
\hline & $\mathrm{A}_{6}$ & 0.714 & 1.400 & 1.190 & 1.000 & 1.250 & 1.000 & 0.155 & & \\
\hline \multirow[t]{7}{*}{$U_{3}$} & Materials & $A_{1}$ & $\mathrm{~A}_{2}$ & $A_{3}$ & $\mathrm{~A}_{4}$ & $A_{5}$ & $A_{6}$ & $w_{A k}$ & & \\
\hline & $A_{1}$ & 1.000 & 1.000 & 1.000 & 0.962 & 1.471 & 1.000 & 0.175 & $\Lambda_{\max }$ & 6.234 \\
\hline & $\mathrm{A}_{2}$ & 1.000 & 1.000 & 1.000 & 1.040 & 0.680 & 1.000 & 0.175 & C.I. & 0.047 \\
\hline & $\mathrm{A}_{3}$ & 1.000 & 1.000 & 1.000 & 0.962 & 1.471 & 1.000 & 0.175 & C.R. & 0.037 \\
\hline & $\mathrm{A}_{4}$ & 1.040 & 0.962 & 1.040 & 1.000 & 0.654 & 0.962 & 0.182 & & \\
\hline & $A_{5}$ & 0.680 & 1.471 & 0.680 & 1.529 & 1.000 & 0.680 & 0.119 & & \\
\hline & $\mathrm{A}_{6}$ & 1.000 & 1.000 & 1.000 & 1.040 & 1.471 & 1.000 & 0.175 & & \\
\hline \multirow[t]{7}{*}{$U_{4}$} & $\begin{array}{l}\text { Quality and } \\
\text { reliability }\end{array}$ & $\mathrm{A}_{1}$ & $\mathrm{~A}_{2}$ & $\mathrm{~A}_{3}$ & $\mathrm{~A}_{4}$ & $A_{5}$ & $\mathrm{~A}_{6}$ & $\mathrm{w}_{\mathrm{Ak}}$ & & \\
\hline & $A_{1}$ & 1.000 & 1.000 & 1.000 & 1.000 & 1.438 & 1.000 & 0.176 & $\Lambda_{\max }$ & 6.183 \\
\hline & $\mathrm{A}_{2}$ & 1.000 & 1.000 & 1.000 & 1.000 & 0.696 & 1.000 & 0.176 & C.I. & 0.037 \\
\hline & $\mathrm{A}_{3}$ & 1.000 & 1.000 & 1.000 & 1.000 & 1.438 & 1.000 & 0.176 & C.R. & 0.029 \\
\hline & $\mathrm{A}_{4}$ & 1.000 & 1.000 & 1.000 & 1.000 & 0.696 & 1.000 & 0.176 & & \\
\hline & $A_{5}$ & 0.696 & 1.438 & 0.696 & 1.438 & 1.000 & 0.696 & 0.122 & & \\
\hline & $\mathrm{A}_{6}$ & 1.000 & 1.000 & 1.000 & 1.000 & 1.438 & 1.000 & 0.176 & & \\
\hline \multirow[t]{7}{*}{$U_{5}$} & Weight & $A_{1}$ & $\mathrm{~A}_{2}$ & $A_{3}$ & $\mathrm{~A}_{4}$ & $A_{5}$ & $A_{6}$ & $w_{A k}$ & & \\
\hline & $A_{1}$ & 1.000 & 1.000 & 1.000 & 1.000 & 1.438 & 1.000 & 0.176 & $\Lambda_{\max }$ & 6.183 \\
\hline & $\mathrm{A}_{2}$ & 1.000 & 1.000 & 1.000 & 1.000 & 0.696 & 1.000 & 0.176 & C.I. & 0.037 \\
\hline & $A_{3}$ & 1.000 & 1.000 & 1.000 & 1.000 & 1.438 & 1.000 & 0.176 & C.R. & 0.029 \\
\hline & $\mathrm{A}_{4}$ & 1.000 & 1.000 & 1.000 & 1.000 & 0.696 & 1.000 & 0.176 & & \\
\hline & $A_{5}$ & 0.696 & 1.438 & 0.696 & 1.438 & 1.000 & 0.696 & 0.122 & & \\
\hline & $\mathrm{A}_{6}$ & 1.000 & 1.000 & 1.000 & 1.000 & 1.438 & 1.000 & 0.176 & & \\
\hline \multirow[t]{7}{*}{$U_{6}$} & Product life span & $A_{1}$ & $\mathrm{~A}_{2}$ & $\mathrm{~A}_{3}$ & $\mathrm{~A}_{4}$ & $A_{5}$ & $\mathrm{~A}_{6}$ & $w_{A k}$ & & \\
\hline & $A_{1}$ & 1.000 & 1.000 & 1.000 & 1.000 & 1.313 & 1.000 & 0.174 & $\Lambda_{\max }$ & 6.101 \\
\hline & $\mathrm{A}_{2}$ & 1.000 & 1.000 & 1.000 & 1.000 & 0.762 & 1.000 & 0.174 & C.I. & 0.020 \\
\hline & $\mathrm{A}_{3}$ & 1.000 & 1.000 & 1.000 & 1.000 & 1.313 & 1.000 & 0.174 & C.R. & 0.016 \\
\hline & $\mathrm{A}_{4}$ & 1.000 & 1.000 & 1.000 & 1.000 & 0.762 & 1.000 & 0.174 & & \\
\hline & $A_{5}$ & 0.762 & 1.313 & 0.762 & 1.313 & 1.000 & 0.762 & 0.132 & & \\
\hline & $\mathrm{A}_{6}$ & 1.000 & 1.000 & 1.000 & 1.000 & 1.313 & 1.000 & 0.174 & & \\
\hline \multirow[t]{7}{*}{$U_{7}$} & Maintenance & $A_{1}$ & $\mathrm{~A}_{2}$ & $A_{3}$ & $\mathrm{~A}_{4}$ & $A_{5}$ & $A_{6}$ & $w_{A k}$ & & \\
\hline & $A_{1}$ & 1.000 & 1.000 & 1.000 & 1.000 & 1.313 & 1.000 & 0.174 & $\Lambda_{\max }$ & 6.101 \\
\hline & $\mathrm{A}_{2}$ & 1.000 & 1.000 & 1.000 & 1.000 & 0.762 & 1.000 & 0.174 & C.I. & 0.020 \\
\hline & $\mathrm{A}_{3}$ & 1.000 & 1.000 & 1.000 & 1.000 & 1.313 & 1.000 & 0.174 & C.R. & 0.016 \\
\hline & $\mathrm{A}_{4}$ & 1.000 & 1.000 & 1.000 & 1.000 & 0.762 & 1.000 & 0.174 & & \\
\hline & $A_{5}$ & 0.762 & 1.313 & 0.762 & 1.313 & 1.000 & 0.762 & 0.132 & & \\
\hline & $\mathrm{A}_{6}$ & 1.000 & 1.000 & 1.000 & 1.000 & 1.313 & 1.000 & 0.174 & & \\
\hline
\end{tabular}

Fig 6: Prioritisation weight for alternatives for the case study 
Table 10 presents the results of the prioritisation weights calculations for the alternatives with respect to the criteria. In this study, the CR values for all of the pair-wise comparison matrices have been found to be less than 0.1 , which is consistent and acceptable. It also shows the largest eigenvalue, $\mathrm{Cl}$ and $\mathrm{CR}$, validating the pair-wise comparison. The results of the overall prioritisation weight for each alternative are presented in Table 11.

Table 10. Summary of prioritisation weight of alternatives for the case study

\begin{tabular}{|ll|c|c|c|}
\hline \multicolumn{1}{|c|}{ Criteria } & $\lambda_{\max }$ & C.I. & C.R. \\
\hline$U_{1}$ & Cost & 6.478 & 0.096 & 0.077 \\
\hline$U_{2}$ & Customer & 6.612 & 0.122 & 0.098 \\
\hline$U_{3}$ & Materials & 6.234 & 0.047 & 0.037 \\
\hline$U_{4}$ & Quality and reliability & 6.183 & 0.037 & 0.029 \\
\hline$U_{5}$ & Weight & 6.183 & 0.037 & 0.029 \\
\hline$U_{6}$ & Product life span & 6.101 & 0.020 & 0.016 \\
\hline$U_{7}$ & Maintenance & 6.101 & 0.020 & 0.016 \\
\hline
\end{tabular}

Table 11. Overall prioritisation weight for alternatives for the case study

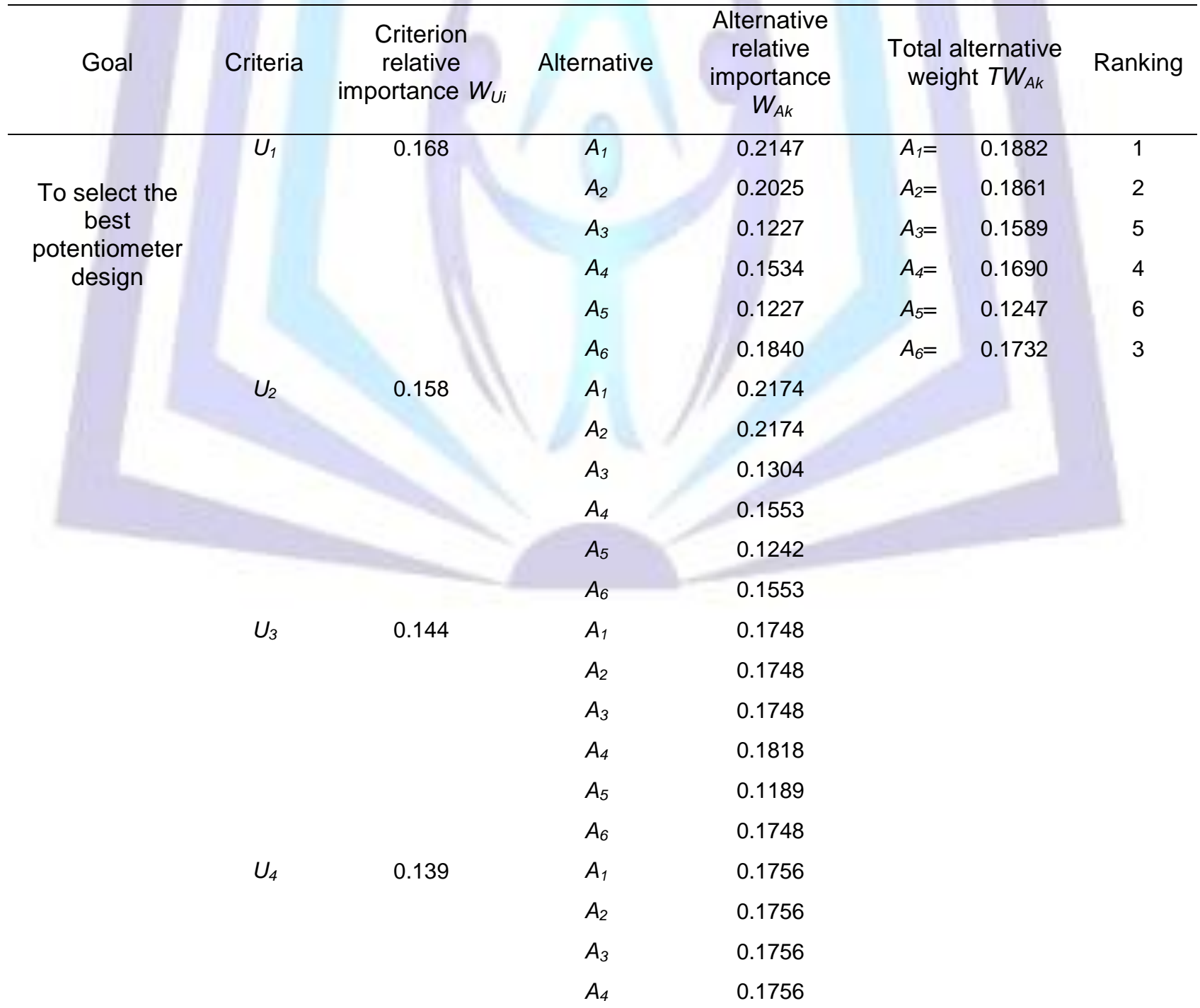




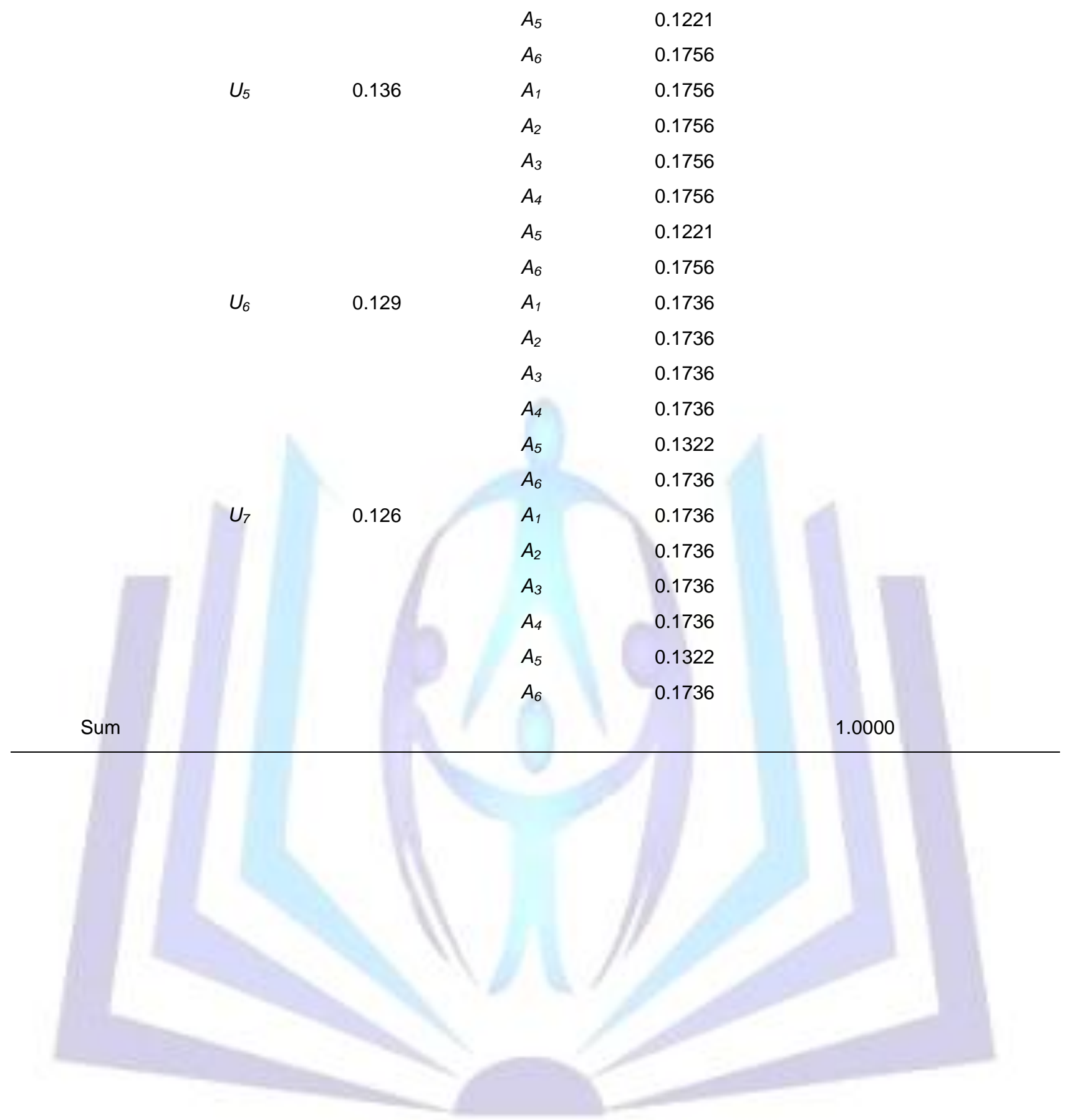


Table 12. Dummy attribute ratings chart for the case study

\begin{tabular}{|c|c|c|c|c|c|c|c|c|c|c|c|c|c|c|c|c|}
\hline \multirow[b]{2}{*}{$a_{j}$} & \multirow{2}{*}{$S_{i}$} & \multicolumn{3}{|c|}{ OEM customer } & \multicolumn{3}{|c|}{ Distributor } & \multicolumn{3}{|c|}{ Sales } & \multicolumn{3}{|c|}{ Top management } & \multicolumn{3}{|c|}{ Designer } \\
\hline & & $T y p$ & Min & Max & $T y p$ & Min & Max & $T y p$ & Min & $\operatorname{Max}$ & $T y p$ & Min & Max & $T y p$ & Min & Max \\
\hline \multirow[t]{6}{*}{$a_{1}$} & $S_{1}$ & 7 & 6.5 & 7.5 & 7 & 6.5 & 7.5 & 7 & 6.5 & 7.5 & 7 & 6.5 & 7.5 & 7 & 6.5 & 75 \\
\hline & $S_{2}$ & 7 & 6.5 & 7.5 & - & 6.5 & 7.5 & 7 & 6.5 & 7.5 & 6 & 5.5 & 6.5 & 6 & 5 & 5 \\
\hline & $S_{3}$ & 4 & 3.5 & 4.5 & 4 & 3.5 & 4.5 & 4 & 3.5 & 4.5 & 4 & 3.5 & 4.5 & 4 & 5 & 4.5 \\
\hline & $S_{4}$ & 5 & 4.5 & 5.5 & 5 & 4.5 & 5.5 & 5 & 4.5 & 5.5 & 5 & 4.5 & 5.5 & 5 & .5 & 5.5 \\
\hline & $S_{5}$ & 4 & 3.5 & 4.5 & 4 & 3.5 & 4.5 & 4 & 3.5 & 4.5 & 1 & & 4.5 & 4 & 5 & 5 \\
\hline & $s$ & 6 & 5.5 & 6.5 & 6 & 5.5 & 6.5 & 6 & 5.5 & 6.5 & 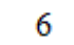 & 5.5 & & 6 & 5 & 6.5 \\
\hline \multirow[t]{6}{*}{$a_{2}$} & $S_{1}$ & 7 & 6.5 & 7. & 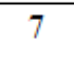 & 6.5 & 1. & 7 & 6.5 & 7.5 & 7 & 0.5 & 7.5 & 7 & 0.5 & 7.5 \\
\hline & $S$ & 7 & 6.5 & 7.5 & 7 & 6.5 & 7.5 & 7 & 6.5 & 7.5 & - & 6.5 & 7.5 & 7 & 5 & .5 \\
\hline & $S_{3}$ & 4 & 3.5 & 4.5 & 4 & 3.5 & 4.5 & 4 & 3.5 & 4.5 & 4 & & 4.5 & 5 & 5 & 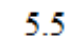 \\
\hline & $S_{4}$ & 5 & 4.5 & 5. & 5 & 4.5 & 5 & 5 & 4.5 & 5.5 & 5 & & 5.5 & 5 & 5 & 5 \\
\hline & $S_{5}$ & 4 & 3.5 & 4 & 4 & 3.5 & 4. & 4 & 3.5 & 4.5 & 4 & & & 4 & 5 & 4.5 \\
\hline & $S_{c}$ & 5 & 4.5 & 5 & 5 & 4.5 & 5. & 5 & 4.5 & 5.5 & 5 & & 5 & 3 & 5 & .5 \\
\hline \multirow[t]{6}{*}{$a_{3}$} & $S_{1}$ & 5 & 4. & 5 & 5 & 4.5 & 5. & - & 4. & 5.5 & 5 & 4 & 5. & 5 & 5 & 5.5 \\
\hline & $S$ & 5 & 4 & 5 & 5 & 4 & 5. & 5 & 4.2 & 5.5 & 5 & 4 & 5 & & 4.5 & 5 \\
\hline & $S_{3}$ & 5 & 4.5 & 5. & 5 & 4.5 & 5 & 5 & 4.5 & 5.5 & 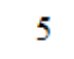 & & & 5 & 5 & .5 \\
\hline & $S_{4}$ & 5 & 4.5 & 5. & 6 & 5.5 & 6. & 5 & 4.5 & 5.5 & 5 & & & 3 & 5 & 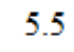 \\
\hline & $S_{5}$ & 3 & 2.5 & 3. & 3 & 2.5 & 3. & 3 & 2.5 & 3.5 & 4 & & & 4 & & .5 \\
\hline & $S_{c}$ & 5 & 4 & 5. & 5 & 4. & 5. & 5 & 4.5 & 5. & 5 & & 5 & 5 & 5 & 5.5 \\
\hline \multirow[t]{6}{*}{$a_{4}$} & $S_{1}$ & 5 & 4. & 5 & 8 & & 5 & 3 & 8 & 3. & 5 & & 5 & & & 5.5 \\
\hline & $S$ & 5 & 4. & 5 & 5 & 4 & 5 & 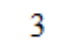 & 2. & 3. & 5 & & & & & .5 \\
\hline & $S_{3}$ & 5 & 4.5 & 5 & 5 & 4. & 5. & 3 & 2.5 & 3.5 & 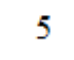 & 7 & 5 & 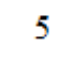 & 5 & 5 \\
\hline & $S_{4}$ & 5 & 4.5 & 5 & 5 & 45 & 5. & 3 & 2.5 & 3.5 & . & & & 5 & 5 & 5 \\
\hline & $S_{5}$ & 3 & 2.5 & 3. & 3 & 2.5 & 3. & 2 & 1.5 & 2.5 & 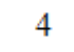 & & & 4 & 5 & .5 \\
\hline & $S$ & 5 & 4.5 & 5 & 5 & 45 & 5. & $?$ & 25 & 3.5 & 5 & & 5 & 5 & 5 & 5.5 \\
\hline \multirow[t]{6}{*}{$a_{5}$} & $S_{1}$ & 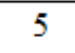 & 4. & 5 & 5 & 4. & 5 & 3 & 2. & 3. & 5 & & 5. & & & 5.5 \\
\hline & $S_{2}$ & 5 & 4 & & 5 & & 5. & 3 & 2 & 3 & 5 & & & & & 5.5 \\
\hline & $S_{3}$ & 5 & 4 & 5 & 5 & 4.5 & 5 & 3 & 2.5 & 3 & 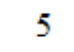 & & & & & 5 \\
\hline & $S_{4}$ & 5 & 4.5 & 5 & 5 & 4.5 & 5. & 3 & 2.5 & 3.5 & . & 4 & 5. & 5 & 4.5 & .5 \\
\hline & $S_{5}$ & 3 & 2.5 & 3 & 3 & 2.5 & 3.5 & 2 & 1.5 & 2.5 & 4 & 3.5 & 4. & 4 & 3.5 & 4.5 \\
\hline & $S_{6}$ & 5 & 4.5 & 5. & 5 & 4.5 & 5.5 & 3 & 2.5 & 3.5 & 5 & 4.5 & 5 & 5 & 4.5 & 5.5 \\
\hline \multirow[t]{6}{*}{$a_{6}$} & $S_{1}$ & 4 & 3.5 & 4 & 4 & 3 & 4. & 4 & 3.5 & 4.5 & . & 3.5 & 4.5 & 5 & 5 & 5.5 \\
\hline & $S_{2}$ & 4 & 3.5 & 4. & 4 & & 4. & 4 & 3.5 & 4. & I. & & 4 & 5 & & $\therefore$ \\
\hline & $S_{3}$ & 4 & 3 & 4. & 4 & 3 & 4. & 4 & 2 & 4 & 4 & & & 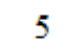 & & .5 \\
\hline & $S_{4}$ & 4 & 3. & 4. & 4 & & 4 & 4 & 3 & 4 & . & & & 5 & & 5.5 \\
\hline & $S$ & 3 & 2.5 & 3. & 3 & 2.5 & 3.5 & 3 & 2.5 & 3.5 & - & 2.5 & 3.5 & 4 & 3.5 & 4.5 \\
\hline & $S_{6}$ & 4 & 3.5 & 4.5 & 4 & 3.5 & 4.5 & 4 & 3.5 & 4.5 & 4 & 3.5 & 4.5 & 5 & 4.5 & 5.5 \\
\hline \multirow[t]{6}{*}{$a_{7}$} & $S_{1}$ & 4 & 3.5 & 4.5 & 4 & 3.5 & 4.5 & 4 & 3.5 & 4.5 & 4 & 3.5 & 4.5 & 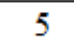 & .5 & 5.5 \\
\hline & $S_{2}$ & 4 & 3. & 4. & 4 & 3.5 & 4. & 4 & 3.5 & 4.5 & 4 & 3.5 & 4.5 & 3 & 4.5 & 5.5 \\
\hline & $S$ & 4 & 3 & 4. & 4 & 3 & 4. & 4 & 3.5 & 4.5 & 4 & 3.5 & 4.5 & 5 & 4.5 & 5.5 \\
\hline & $S$ & 4 & 3 & 4. & 4 & 3. & 4. & 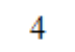 & 3.5 & 4. & . & 3. & 4. & 3 & 4.5 & 5.5 \\
\hline & $S$ & 3 & 2 & 3. & 3 & 2.5 & 3. & 3 & 2.5 & 3.5 & - & 2.3 & 3.5 & 4 & 3.5 & 4.5 \\
\hline & $S_{6}$ & 4 & 3.5 & 4.5 & 4 & 3.5 & 4.5 & 4 & 3.5 & 4.5 & 4 & 3.5 & 4.5 & 5 & 4.5 & 5.5 \\
\hline
\end{tabular}

\section{Verification using Rough-Grey Analysis}

There is a grey information system $T=\left(U, A, V, f_{\otimes}\right)$ for the selection of alternatives. The grey decision table is expressed by $T=\left(U, A \cup D, f_{\otimes}\right) . U=\left\{S_{i}, i=1,2, \ldots, 6\right\}$ are six potential alternatives for seven attributes 
$A=\left\{a_{j}, j=1,2, \ldots, 7\right\}$. The seven attributes include qualitative attributes and quantitative attributes. Similar to the previous sub-sections, $a_{6}$ is a benefit attribute, for which larger values are better. $a_{1}, a_{2}, a_{3}, a_{4}, a_{5}$ and $a_{7}$ are cost attributes, for which smaller values are better. The selection structure is shown in Fig 7.

Goal

Conditional attributes

Alternatives

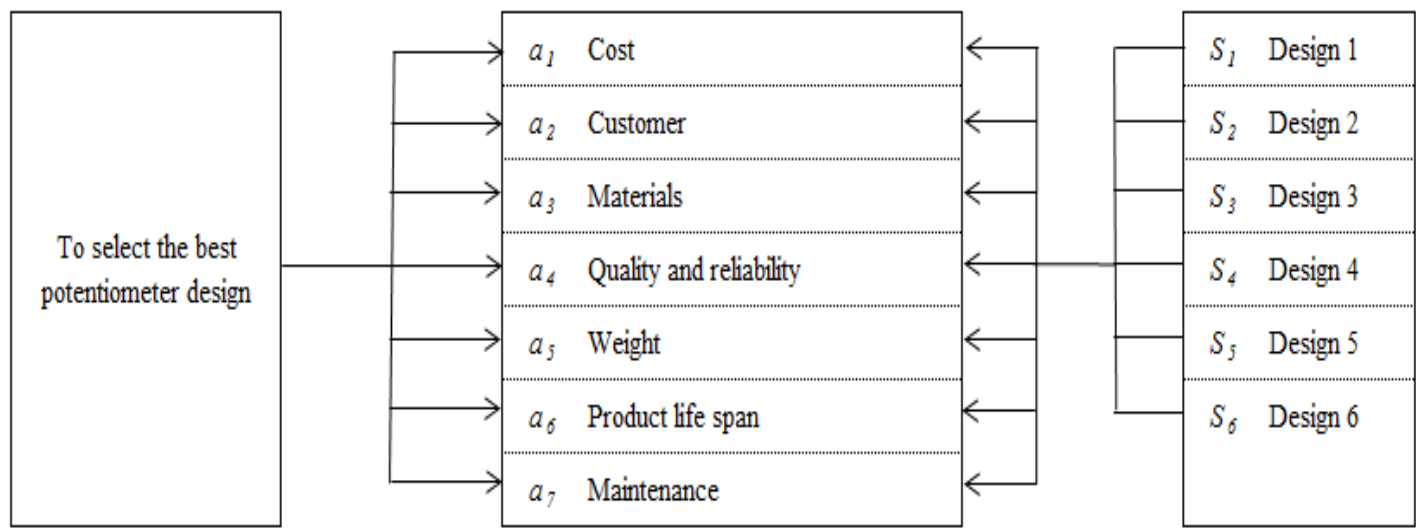

Fig 7: Selection structure for the case study

Table 13 depicts the attribute rating value for the case study based on the survey results from five groups of decision makers who expressed their preferences on attributes and decision and then, the grey decision table is formed, as shown in Table 14. The next step is to normalise the grey decision table and the grey normalised decision table is shown in Table 15.

Table 13. Attribute rating value for the case study

\begin{tabular}{cccccccc}
\hline$a_{j}$ & $S_{i}$ & $\begin{array}{c}\text { OEM } \\
\text { customer } \\
D_{1}\end{array}$ & Distributor & Sales & $\begin{array}{c}\text { Top } \\
\text { management }\end{array}$ & Designer \\
& & $D_{2}$ & $D_{3}$ & $D_{4}$ & $D_{5}$ & \\
\hline$a_{1}$ & & & & & & & \\
& $S_{1}$ & $G$ & $G$ & $G$ & $G$ & $G$ & {$[6.5,7.5]$} \\
& $S_{2}$ & $G$ & $G$ & $G$ & G/MG & G/MG & {$[6.1,7.1]$} \\
& $S_{3}$ & F/MP & F/MP & F/MP & F/MP & F/MP & {$[3.5,4.5]$} \\
& $S_{4}$ & MG/F & MG/F & MG/F & MG/F & MG/F & {$[4.5,5.5]$} \\
& $S_{5}$ & F/MP & F/MP & F/MP & F/MP & F/MP & {$[3.5,4.5]$} \\
$S_{6}$ & G/MG & G/MG & G/MG & G/MG & G/MG & {$[5.5,6.5]$}
\end{tabular}

$a_{2}$

$\begin{array}{lcccccc}s_{1} & \mathrm{G} & \mathrm{G} & \mathrm{G} & \mathrm{G} & \mathrm{G} & {[6.5,7.5]} \\ s_{2} & \mathrm{G} & \mathrm{G} & \mathrm{G} & \mathrm{G} & \mathrm{G} & {[6.5,7.5]} \\ s_{3} & \mathrm{~F} / \mathrm{MP} & \mathrm{F} / \mathrm{MP} & \mathrm{F} / \mathrm{MP} & \mathrm{F} / \mathrm{MP} & \mathrm{MG} / \mathrm{F} & {[3.7,4.7]} \\ S_{4} & \mathrm{MG} / \mathrm{F} & \mathrm{MG} / \mathrm{F} & \mathrm{MG} / \mathrm{F} & \mathrm{MG} / \mathrm{F} & \mathrm{MG} / \mathrm{F} & {[4.5,5.5]} \\ S_{5} & \mathrm{~F} / \mathrm{MP} & \mathrm{F} / \mathrm{MP} & \mathrm{F} / \mathrm{MP} & \mathrm{F} / \mathrm{MP} & \mathrm{F} / \mathrm{MP} & {[3.5,4.5]} \\ S_{6} & \mathrm{MG} / \mathrm{F} & \mathrm{MG} / \mathrm{F} & \mathrm{MG} / \mathrm{F} & \mathrm{MG} / \mathrm{F} & \mathrm{MG} / \mathrm{F} & {[4.5,5.5]}\end{array}$

$a_{3}$

$\begin{array}{lllllll}S_{1} & \mathrm{MG} / \mathrm{F} & \mathrm{MG} / \mathrm{F} & \mathrm{MG} / \mathrm{F} & \mathrm{MG} / \mathrm{F} & \mathrm{MG} / \mathrm{F} & {[4.5,5.5]} \\ S_{2} & \mathrm{MG} / \mathrm{F} & \mathrm{MG} / \mathrm{F} & \mathrm{MG} / \mathrm{F} & \mathrm{MG} / \mathrm{F} & \mathrm{MG} / \mathrm{F} & {[4.5,5.5]} \\ S_{3} & \mathrm{MG} / \mathrm{F} & \mathrm{MG} / \mathrm{F} & \mathrm{MG} / \mathrm{F} & \mathrm{MG} / \mathrm{F} & \mathrm{MG} / \mathrm{F} & {[4.5,5.5]} \\ S_{4} & \mathrm{MG} / \mathrm{F} & \mathrm{G} / \mathrm{MG} & \mathrm{MG} / \mathrm{F} & \mathrm{MG} / \mathrm{F} & \mathrm{MG} / \mathrm{F} & {[4.7,5.7]}\end{array}$




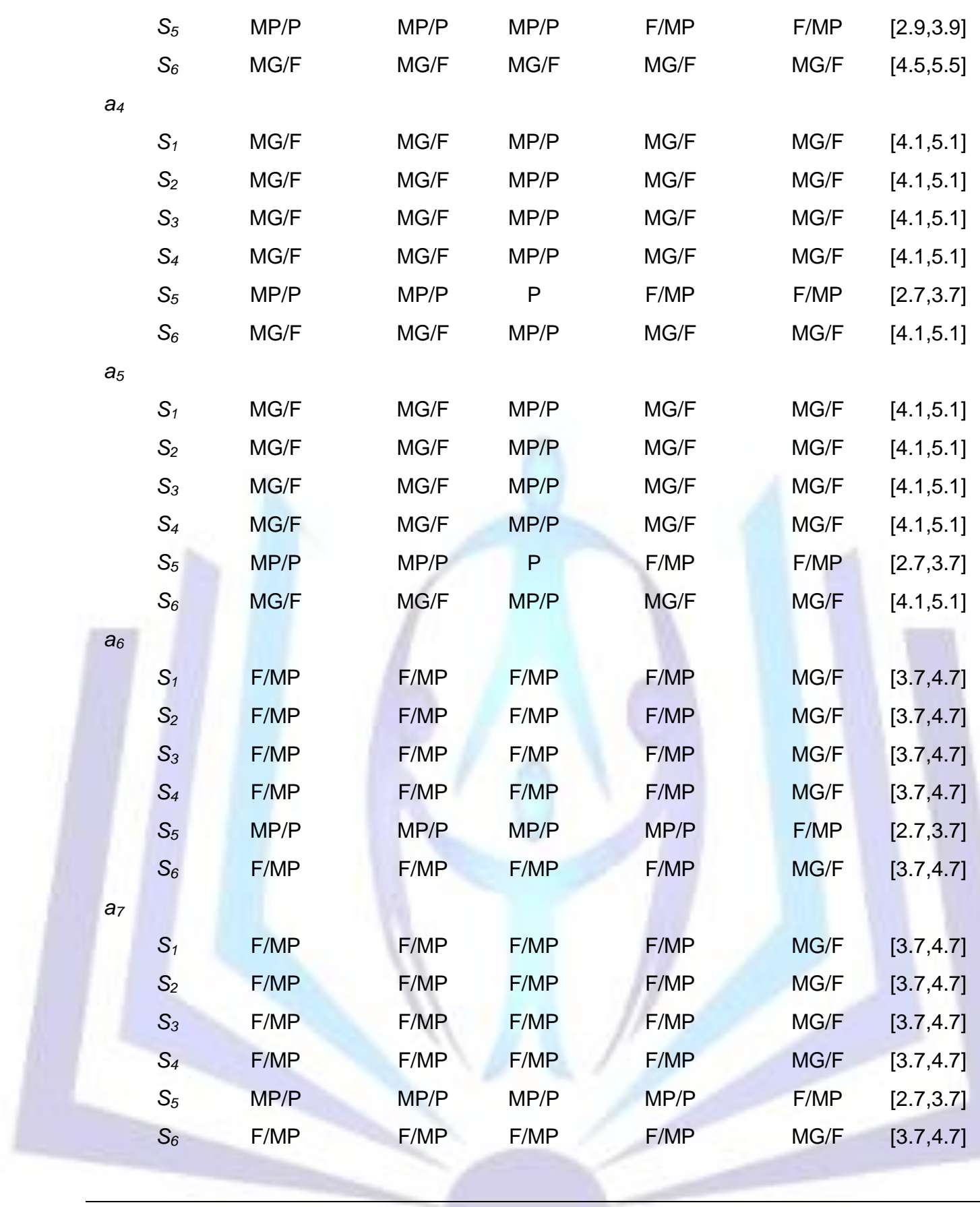

Table 14. Grey decision table for the case study

\begin{tabular}{ccccccc}
\hline Alternatives & $S_{1}$ & $S_{2}$ & $S_{3}$ & $S_{4}$ & $S_{5}$ & $S_{6}$ \\
\hline$a_{1}$ & {$[6.5,7.5]$} & {$[6.1,7.1]$} & {$[3.5,4.5]$} & {$[4.5,5.5]$} & {$[3.5,4.5]$} & {$[5.5,6.5]$} \\
$a_{2}$ & {$[6.5,7.5]$} & {$[6.5,7.5]$} & {$[3.7,4.7]$} & {$[4.5,5.5]$} & {$[3.5,4.5]$} & {$[4.5,5.5]$} \\
$a_{3}$ & {$[4.5,5.5]$} & {$[4.5,5.5]$} & {$[4.5,5.5]$} & {$[4.7,5.7]$} & {$[2.9,3.9]$} & {$[4.5,5.5]$} \\
$a_{4}$ & {$[4.1,5.1]$} & {$[4.1,5.1]$} & {$[4.1,5.1]$} & {$[4.1,5.1]$} & {$[2.7,3.7]$} & {$[4.1,5.1]$} \\
$a_{5}$ & {$[4.1,5.1]$} & {$[4.1,5.1]$} & {$[4.1,5.1]$} & {$[4.1,5.1]$} & {$[2.7,3.7]$} & {$[4.1,5.1]$} \\
$a_{6}$ & {$[3.7,4.7]$} & {$[3.7,4.7]$} & {$[3.7,4.7]$} & {$[3.7,4.7]$} & {$[2.7,3.7]$} & {$[3.7,4.7]$} \\
$a_{7}$ & {$[3.7,4.7]$} & {$[3.7,4.7]$} & {$[3.7,4.7]$} & {$[3.7,4.7]$} & {$[2.7,3.7]$} & {$[3.7,4.7]$} \\
\hline Decision & 2 & 2 & 1 & 1 & 1 & 2 \\
\hline
\end{tabular}


Table 15. Grey normalised for the case study

\begin{tabular}{ccccccc}
\hline Alternatives & $S_{1}$ & $S_{2}$ & $S_{3}$ & $S_{4}$ & $S_{5}$ & $S_{6}$ \\
\hline$a_{1}{ }^{*}$ & {$[0.867,1]$} & {$[0.813,0.947]$} & {$[0.467,0.6]$} & {$[0.6,0.733]$} & {$[0.467,0.6]$} & {$[0.733,0.867]$} \\
$a_{2}{ }^{*}$ & {$[0.867,1]$} & {$[0.867,1]$} & {$[0.493,0.627]$} & {$[0.6,0.733]$} & {$[0.467,0.6]$} & {$[0.6,0.733]$} \\
$a_{3}{ }^{*}$ & {$[0.789,0.965]$} & {$[0.789,0.965]$} & {$[0.789,0.965]$} & {$[0.825,1]$} & {$[0.509,0.684]$} & {$[0.789,0.965]$} \\
$a_{4}{ }^{*}$ & {$[0.804,1]$} & {$[0.804,1]$} & {$[0.804,1]$} & {$[0.804,1]$} & {$[0.529,0.725]$} & {$[0.804,1]$} \\
$a_{5}{ }^{*}$ & {$[0.804,1]$} & {$[0.804,1]$} & {$[0.804,1]$} & {$[0.804,1]$} & {$[0.529,0.725]$} & {$[0.804,1]$} \\
$a_{6}{ }^{*}$ & {$[0.787,1]$} & {$[0.787,1]$} & {$[0.787,1]$} & {$[0.787,1]$} & {$[0.574,0.787]$} & {$[0.787,1]$} \\
$a_{7}{ }^{*}$ & {$[0.787,1]$} & {$[0.787,1]$} & {$[0.787,1]$} & {$[0.787,1]$} & {$[0.574,0.787]$} & {$[0.787,1]$} \\
\hline Decision & 2 & 2 & 1 & 1 & 1 & 2
\end{tabular}

The GRA is a numerical measure of the relationship between comparative values and objective values; the numeric values are between 0 and 1. By the rule that the design corresponding to the maximum value of GRG is the most suitable design, the grade is $S_{1}>S_{2}>S_{6}>S_{4}>S_{3}>S_{5}$, as shown in Table 16 .

Table 16. Grey relational grade for the case study

\begin{tabular}{|c|c|c|c|c|c|c|c|c|c|}
\hline \multirow[t]{2}{*}{ GRG } & \multicolumn{7}{|c|}{ Conditional attributes } & \multirow[t]{2}{*}{ Total } & \multirow[t]{2}{*}{ Ranking } \\
\hline & $a_{1}$ & $a_{2}$ & $a_{3}$ & $a_{4}$ & $a_{5}$ & $a_{6}$ & $a_{7}$ & & \\
\hline$\square 01$ & 0.167 & 0.167 & 0.148 & 0.167 & 0.167 & 0.167 & 0.167 & 1.148 & 1 \\
\hline$\square 02$ & 0.144 & 0.167 & 0.148 & 0.167 & 0.167 & 0.167 & 0.167 & 1.126 & 2 \\
\hline$\square 03$ & 0.000 & 0.011 & 0.148 & 0.167 & 0.167 & 0.167 & 0.167 & 0.826 & 5 \\
\hline$\square 04$ & 0.055 & 0.055 & 0.167 & 0.167 & 0.167 & 0.167 & 0.167 & 0.944 & 4 \\
\hline$\square 05$ & 0.000 & 0.000 & 0.000 & 0.000 & 0.000 & 0.000 & 0.000 & 0.000 & 6 \\
\hline$\square 06$ & 0.111 & 0.055 & 0.148 & 0.167 & 0.167 & 0.167 & 0.167 & 0.981 & 3 \\
\hline
\end{tabular}

\section{Analysis}

The Fuzzy-AHP analysis for the proposed approach suggests that Design 1 with weight of 0.1882 should be given the highest priority. Among the six alternatives selected in this study, the second most important alternative is Design 2 with a weight of 0.1861 , followed by Design 6 (0.1732), Design 4 (0.1690), Design 3 (0.1589) and Design 5 (0.1247).

From the GRG results of verification process using the Rough-Grey analysis method, the most suitable design is Design 1 $\left(\Gamma_{01}=1.148\right)$, followed by Design $2\left(\Gamma_{02}=1.126\right)$, Design $6\left(\Gamma_{06}=0.981\right)$, Design $4\left(\Gamma_{04}=0.944\right)$, Design 3 $\left(\Gamma_{03}=0.826\right)$ and Design $5\left(\Gamma_{05}=0.000\right)$. All of these results are consistent with the results of Fuzzy-AHP method.

Fig 8 depicts the completion period for the case study based on the previous development record of the company. The completion period for the case study shows that the design evaluation using the newly proposed approach (HoQ, FuzzyAHP, Rough-Grey Analysis) was completed within eight months compared with the targeted time of nine months.

Case study of the proposed approach

\begin{tabular}{|c|c|c|c|c|c|}
\hline \multirow{2}{*}{ Event } & \multicolumn{2}{|c|}{ Duration to complete } & \multirow{2}{*}{ Event } & \multicolumn{2}{|c|}{ Duration to complete } \\
\hline & Target & Actual & & Target & Actual \\
\hline Survey results & 3 months & 3 months & Evaluation & 6 months & 5 months \\
\hline
\end{tabular}

Total completion
Plan
\begin{tabular}{|c|c|}
\hline 9 months & Actual \\
\hline
\end{tabular}

Fig 8: Total completion period for the case study 
The results of the proposed approach has demonstrated its advantage by successfully improving the development time compared with the target. However, this result is valid only for those types of products that have the same degree of complexity as those used in this research.

\section{CONCLUSIONS}

This research has introduced the preliminary stage of the design evaluation process using the HoQ method with the used of scale of "Weighting criteria" for survey process and according to the case study data; the designers have managed to choose the exact criteria and reduce the number of design criteria of the product.

Selecting the exact criteria and the application of new method of computing the priority of element has simplified the PCM operation during evaluation process using the Fuzzy-AHP method with fewer numbers of pair-wise comparisons. This has helped the designers to achieve the desired level of criteria consistency as early as possible. This has been shown in the case study undertaken in this research.

The final stage was the verification and validation process using the Rough-Grey Analysis method with the application of new method of quantifying the attribute ratings value, which has helped in reducing the unnecessary iteration process, as happened when using the conventional Fuzzy-AHP method. From the case study data, all of the evaluation results are valid and have been confirmed by the company directly involved in the case study.

The results of the example presented in this research show that the idea of using the integration and interfacing technique of Fuzzy-AHP with HoQ and Rough-Grey Analysis, provides designers with another alternative to the existing methods, for the performance of design evaluation in the early stages of product development. The proposed framework has successfully helped the designers to reduce product development time.

This research not only benefits the area of design evaluation in product development but it can be applied to any other area associated with a decision-making process. The efficacy of the proposed method could be extended by applying it in different conditions or to products of different complexity.

\section{REFERENCES}

[1] W. Li, Li, Y., Wang, J., Liu, X., "The Process Model to Aid Innovation of Products Conceptual Design," Expert Systems with Applications, vol. 37, pp. 3574-3587, 2010.

[2] T. Edwards, Battisti, G., W. P. McClendon Jr., Denyer, D., Neely, A., Pathways to Value How UK Firms Create More Value Using Innovation Strategically, 1 ed. London: Advanced Institure of Management Research (AIM), 2005.

[3] S. Brown, Eisenhardt, K., "Product development: Past research, present findings, and future directions," Academy of Management Review, pp. 343-378, 1995.

[4] A. Griffin, Hauser, J., "Integrating R\&D and marketing: A review and analysis of the literature," Journal of Product Innovation Management, vol. 13, pp. 191-215, 1996.

[5] V. Krishnan, Ulrich, K., "Product development decisions: A review of the literature," Management Science, vol. 1-21, 2001.

[6] H. Chesbrough, Teece, D., "Organizing for innovation: When is virtual virtuous?," Harvard Business Review, vol. 80, pp. 127-134, 2002.

[7] Z. Ayag, Odzemir, R. G., "A hybrid approach to concept selection through fuzzy analytic network process," Computers \& Industrial Engineering, vol. 56, pp. 368-379, 2008.

[8] F. Lee, Santiago, M., Creativity in New Product Development : An Evolutionary Integration, 1 ed. USA: ButterworthHeinemann, 2008.

[9] S. Minderhoud, Fraser, P., "Shifting paradigms of product development in fast and dynamic markets," Reliability Engineering and System Safety, vol. 88, pp. 127-135, 2005.

[10] S. Pugh, Total Design: Integrated Methods for Successful Product Engineering. Wolkingham, England: AdditionWesley Publishing Company, 1996.

[11] N. F. O. Ebuomwan, Sivaloganathan, S., Jebb, A., "A Survey of Design Philosophies, Models, Methods and Systems," Proceedings of the Institution of Mechanical Engineers Part B - Journal of Engineering Manufacture, vol. 210, pp. 301-320, 1996.

[12] G. Pahl, Beitz, W., Feldhuson, J., Grote, K. H., Engineering Design: A Systematic Approach, 3rd ed. London: Springer-Verlag London Ltd., 2007.

[13] S. Finger, Dixon, J. R., "A Review of Research in Mechanical Engineering Design. Part II: Representations, Analysis, and Design for the Life Cycle," Research in Engineering Design, vol. 1, pp. 121-137, 1989.

[14] S. K. Chandrasegaran, Ramani, K., Sriram, R. D., Horváth, I., Bernard, A., Harik, R. F., Gao, W., "The evolution, challenges, and future of knowledge representation in product design systems," Computer-Aided Design, vol. 45, pp. 204-228, 2013. 
[15] F. M. Turan, Omar, B., "In situ design evaluation for product life cycle management using Fuzzy-AHP approach," in International Conference on Applications and Design in Mechanical Engineering (ICADME 2012), Penang, Malaysia, 2012.

[16] F. M. Turan, Omar, B., "The Integration of HOQ and Fuzzy-AHP for Design Concept Evaluation," Applied Mechanics and Materials, vol. 315, pp. 25-29, 2013.

[17] W. Hsu, M. Y. Woon, I., "Current Research in the Conceptual Design of Mechanical Products," Computer-Aided Design, vol. 30, pp. 377-389, 1998.

[18] E. Subrahmanian, Rachuri, S., Fenves, S. J., Foufou, S., Sriram, R. D., "Product lifecycle management support: A challenge in supporting product design and manufacturing in a networked economy," International Journal of Product Lifecycle Management, vol. 1, pp. 4-25, 2005.

[19] O. Shai, Reich, Y., Rubin, D., "Creative conceptual design: extending the scope by infused design," Computer-Aided Design, vol. 41, pp. 117-135, 2007.

[20] X. Ye, Liu, H., Chen, L., Chen, Z., Pan, X., Zhang, S., "Reverse innovative design - an integrated product design methodology," Computer-Aided Design, vol. 40, pp. 812-827, 2008.

[21] S. Liu, Boyle, I. M., "Engineering design: perspectives, challenges, and recent advances," Journal of Engineering Design, vol. 20, pp. 7-19, 2009.

[22] B. Lotter, Manufacturing Assembly Handbook. Boston, USA: Butterworth-Heinemann, 1986.

[23] J. L. Nevins, Whitney, D., Concurrent design of products and processes - A strategy for the next generation in manufacturing. New York: McGraw-Hill, 1989.

[24] D. G. Ullman, The Mechanical Design Process, 4 ed. New York: McGraw-Hill, 2009.

[25] L. Y. Zhai, Khoo, L. P., Zhong, Z. W., "Design Concept Evaluation in Product Development using Rough Sets and Grey Relation Analysis," Expert Systems with Applications, vol. 36, pp. 7072-7079, 2009.

[26] X. Geng, Chu, X., Zhang, Z., "A new integrated design concept evaluation approach based on vague sets," Expert Systems with Applications, vol. 37, pp. 6629-6638, 2010.

[27] G. Green, "Towards integrated evaluation: validation of models," Journal of engineering design, vol. 11, pp. 121-132, 2000.

[28] M. A. Rosenman, "Qualitative evaluation for topological specification in conceptual design," Applications and Techniques of Artificial Intelligence in Engineering, vol. 2, pp. 311-326, 1993.

[29] G. Green, "Modeling concept design evaluation," Artificial intelligence for engineering design, analysis and manufacturing, vol. 11, pp. 211-217, 1997.

[30] K. Ulrich, Eppinger, S, Product design and development, 5th edition. New York: McGraw-Hill Inc., 2005.

[31] M. Millson, Miles, B., Tennant. C., "Effective new product introduction in SMEs.," in Paper presented at the Proceeding of 2nd International Conference on Manufacturing Technology, Sheffield Hallam University, United Kingdom, 2004.

[32] P. R. Childs, Mechanical design. Oxford: Elsevier Butterworth-Heinemann, 2004.

[33] E. Francis, Tay, H., Gu, J., "Product Modeling for Conceptual Design Support," Computer in Industry, vol. 48, pp. 143155,2002

[34] Y. C. Liu, Bligh, T., Chakrabarti, A., "Towards an 'ideal' approach for concept generation," Journal of design studies, vol. 24, pp. 341-355, 2003.

[35] A. M. Lovatt, Shercliff, H.R. , "Manufacturing process selection in engineering design. Part 2: an approach for creating task-based process selection procedures," Journal of material and design, vol. 19, pp. 217-230, 1998.

[36] M. J. Scott, "Quantifying Certainty in Design Decisions: Examining AHP," in ASME Design Engineering Technical Conferences (DETC2002), 2002.

[37] Z. Ayag, Odzemir, R. G., "A combined fuzzy AHP-goal programming approach to assembly-line selection," Journal of Intelligent and Fuzzy Systems, vol. 18, pp. 345-362, 2007.

[38] M. B. Javanbarg, Scawthorn, C., Kiyono, J., Shahbodaghkhan, B., "Fuzzy AHP-based multicriteria decision making systems using particle swarm optimization," Expert Systems with Applications, vol. 39, pp. 960-966, 2012.

[39] E. Triantaphyllou, Lin, C. T., "Development and evaluation of five fuzzy multiattribute decision-making methods," International Journal of Approximate Reasoning, vol. 14, pp. 281-310, 1996.

[40] O. Duran, Aguilo, J., "Computer-aided machine-tool selection based on a fuzzy-AHP approach," Expert Systems with Applications, vol. 34, pp. 1787-1794, 2007. 
[41] L. C. Chen, Lin, L., "Optimisation of product configuration design using functional requirements and constraints," Research in engineering design, vol. 13, pp. 167-182, 2002.

[42] S. M. Ordoobadi, Mulvaney, N. J., "Development of a justification tool for advanced manufacturing technologies: system-wide benefits value analysis," Journal of engineering and technology management, vol. 18, pp. 157-184, 2001.

[43] B. Nepal, Yadav, O. P., Murat, A., "A fuzzy-AHP approach to prioritization of CS attributes in target planning for automotive product development," Expert Systems with Applications, vol. 37, pp. 6775-6786, 2010.

[44] G. D. Li, Yamaguchi, D., Nagai, M., "A grey-based rough decision-making approach to supplier selection," International Journal of Advanced Manufacturing Technology, vol. 36, pp. 1032-1040, 2008.

[45] C. Bai, Sarkis, J., "Integrating sustainability into supplier selection with grey system and rough set methodologies," Int. J.ProductionEconomics, vol. 124, pp. 252-264, 2010.

[46] C. Bai, Sarkis, J., "Evaluating supplier development programs with a grey based rough set methodology," Expert Systems with Applications, vol. 38, pp. 13505-13517, 2011.

\section{Author' biography with Photo}

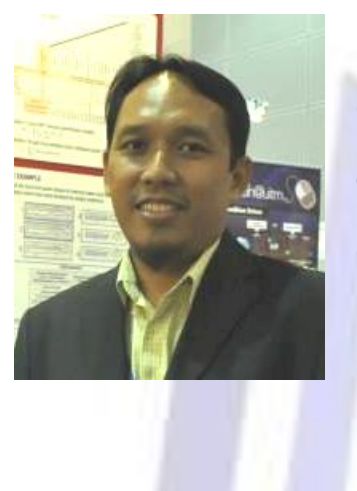

Dr. Faiz Mohd Turan is currently a Senior Lecturer of Faculty of Manufacturing Engineering in the Universiti Malaysia Pahang, Malaysia. He graduated with Associate Degree in electronic control engineering from Yonago National College of Technology, Japan in 1997, and BEng (first class honours) in electrical engineering from the Universiti Teknologi Malaysia, Malaysia in 2010 . $\mathrm{He}$ obtained his PhD degree in mechanical engineering from Universiti Tun Hussein Onn Malaysia, Malaysia in 2014. His research interests include engineering design, lean manufacturing and controller design. He can be reached at faizmt@ump.edu.my

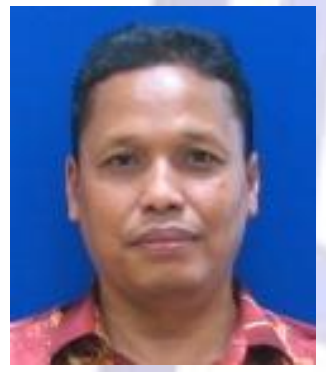

Dr. Badrul Omar is currently an Associate Professor of Faculty of Mechanical and Manufacturing Engineering in the Universiti Tun Hussein Onn Malaysia, Malaysia. He graduated with BEng in mechanical engineering from University of Leeds, United Kingdom, and Master's degree with distinction in Computer Aided Engineering from Liverpool John Moore University, United Kingdom in 1989. He obtained his PhD degree from the University of Leeds, United Kingdom in 2008. He has various research interests in mechanical engineering and some interest as well in engineering education. He can be reached at <badrul@uthm.edu.my> 